\title{
Developing a framework for predicting the impact of ITS/CVO technology in developing countries
}

Mazen Turk

West Virginia University

Follow this and additional works at: https://researchrepository.wvu.edu/etd

\section{Recommended Citation}

Turk, Mazen, "Developing a framework for predicting the impact of ITS/CVO technology in developing countries" (2000). Graduate Theses, Dissertations, and Problem Reports. 1058.

https://researchrepository.wvu.edu/etd/1058

This Thesis is protected by copyright and/or related rights. It has been brought to you by the The Research Repository @ WVU with permission from the rights-holder(s). You are free to use this Thesis in any way that is permitted by the copyright and related rights legislation that applies to your use. For other uses you must obtain permission from the rights-holder(s) directly, unless additional rights are indicated by a Creative Commons license in the record and/ or on the work itself. This Thesis has been accepted for inclusion in WVU Graduate Theses, Dissertations, and Problem Reports collection by an authorized administrator of The Research Repository @ WVU. For more information, please contact researchrepository@mail.wvu.edu. 


\title{
DEVELOPING A FRAMEWORK FOR PREDICTING THE IMPACT OF ITS/CVO TECHNOLOGY IN DEVELOPING COUNTRIES
}

\author{
Mazen Turk
}

\begin{abstract}
Thesis Submitted to the College of Engineering and Mineral Resources at West Virginia University in partial fulfillment of the requirements for the degree of
\end{abstract}

\author{
Master of Science \\ in \\ Civil Engineering
}
Dr. David Martinelli, Ph.D., Chair
Dr. Darrell Dean, Ph.D.
Dr. Ronald Eck, Ph.D.

Department of Civil and Environmental Engineering

$$
\begin{gathered}
\text { Morgantown, West Virginia } \\
2000
\end{gathered}
$$

Keywords: Transportation, Impact, Prediction, ITS, CVO, Microeconomics. 


\section{ABSTRACT \\ Developing A Framework for Predicting the Impact of ITS/CVO Technology in Developing Countries}

\section{Mazen Turk}

Understanding how a transportation system responds to the implementation of new technologies will result in better policy decisions. Recently planners and policy makers have come to the understanding that forecasting alone no longer plays the central role in predicting impact. The process of information collection, analysis, and decisionmaking should rather be viewed from a wider perspective in order to allow for explicit assessment of what is needed for both short and long-term planning.

The prediction process must consider all aspects of a global complex transportation system, and activity system focusing on understanding their interrelations and interdependencies. In developing countries, especially, socioeconomic and sociopolitical issues are dynamic in nature and hard to foresee. The changes will impact the demand on the transportation system, causing it to react and behave in predictable and unpredictable manners.

This study focuses on freight mobility in developing countries. System improvements depend on state of the art technologies to be deployed in the Transportation Infrastructure. Intelligent Transportation Systems and Commercial Vehicle Operation technologies (ITS/CVO) although a significant investment, offer many improvement alternatives. This study develops a framework for predicting the impact of new technologies on the global transportation system in developing countries. This is done in an effort to reduce cost and improve safety, efficiency and level of service.

The task will be divided into three sections. The first will entail looking at prediction from a global perspective. This will specify the elements that affect changes in flow volumes in a particular transportation system. The second section will look at the system from a conceptual view. Microeconomic theory is used to analyze the system. The third section will focus on implementation. This section will devise model formulation, what data to use, and how to use it.

The motivation for developing the framework emanates from the major modernization program that The Port of Beirut has embarked on in an effort to make it a competitive port in the region. With large investments being injected in transportation projects, planners will make use of this framework in order to partake in better decision making. Improving transportation investment decision making will provide economic growth and act as the backbone to integrate all sectors of the economy such as trade, manufacturing, and finance. 


\section{TABLE OF CONTENTS}

TITLE PAGE i

ABSTRACT ii

TABLE OF CONTENT

LIST OF TABLES vi

LIST OF FIGURES vii

CHAPTER 1: INTRODUCTION

$\begin{array}{ll}\text { 1.1 Background } & 1\end{array}$

$\begin{array}{ll}\text { 1.2 Problem Statement } & 3\end{array}$

$\begin{array}{ll}1.3 \text { Objective } & 4\end{array}$

1.4 Summary of Chapters $\quad 6$

CHAPTER 2: BACKGROUND ON COMMERCIAL VEHICLE OPERATION

$\begin{array}{lr}\text { 2.1 ITS Technologies } & 9\end{array}$

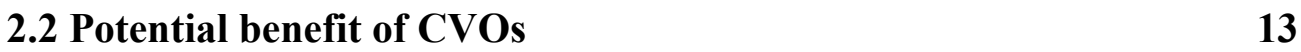

CHAPTER 3: LITERATURE REVIEW

$\begin{array}{lr}3.1 \text { Introduction } & 19\end{array}$

$\begin{array}{ll}\text { 3.2 The Rational behind Literature Used } & 20\end{array}$

$\begin{array}{ll}\text { 3.2.1 Transportation Economics } & 21\end{array}$

3.2.2 Transportation Planning and Operation 25 


\section{CHAPTER 4: GLOBAL LEVEL FORMULATION}

$\begin{array}{lr}4.1 \text { Introduction } & 29\end{array}$

4.2 Option Intervening to Impact the Flow Volumes 30

4.2.1 The Transportation System Options 30

4.2.2 The Activity System Options 32

4.2 Supply and Demand Models 33

4.3 Impacts On Different Groups

\section{CHAPTER 5: CONCEPTUAL LEVEL FORMULATION}

$\begin{array}{ll}5.1 \text { Introduction } & 38\end{array}$

$\begin{array}{ll}\text { 5.2 Developing a Supply Function } & 38\end{array}$

5.2.1 The Supply Model 41

5.3 Developing a Demand Function 43

5.3.2 The Demand Model $\quad 45$

$\begin{array}{ll}5.4 \text { Equilibrium } & 46\end{array}$

5.4.1 Shifts in the Activity System and the

$\begin{array}{ll}\text { Transportation System } & 47\end{array}$

5.4.2 Quantifying User Benefit 49

CHAPTER 6: IMPLIMENTATION OF THE FRAMEWORK

$\begin{array}{ll}\text { 6.1 A Case Study } & 61\end{array}$

6.2 Socioeconomic and Sociopolitics variables considered 62 
6.2.1 Background on socioeconomic and political issues for the country of Lebanon 62

6.2.2 Demand Estimation

CHAPTER 7 CONCLUSION AND RECOMMENDATIONS

7.1Conclusions and Recommendation

REFERENCES

BIBLIOGRAPHY

75

APPENDIX A

78 


\section{LIST OF TABLES}

Table 2.1: Relevant ITS/CVO projects investigated

Table 5.1: Reported benefits or costs savings associated with ITS/CVO implementation

51

Table 5.2: Relevant data for capacity analysis for selected countries

52

Table 5.3: Relevant data for demand analysis for selected countries

Table 6.1: Socioeconomic variables for Lebanon

66

Table 6.2: Values from the regression analysis

67

Table 6.3: The correlation between predicted flow and its cost

68 


\section{LIST OF FIGURES}

Figure 1.1: The common services between ITS/CVO technology 3

Figure 2.1: The license Plate Recognition System (LPR) 16

Figure 2.2: Figure showing the Advanced Vehicle Routing System 17

Figure 2.3: The weight in motion System (WIM) 18

Figure 3.1: The basic relations between the activity system, the transportation system, and the flow 28

Figure 4.1: The basic framework for prediction of flow 37

Figure 5.1: An illustrative user cost or price-volume relationship $\quad 54$

Figure 5.2: An illustrative for linear demand function 55

Figure 5.3: An illustration of equilibrium between demand and supply $\quad 56$

Figure 5.4: An illustration of converging equilibrium between demand and supply

Figure 5.5: An illustration of diverging equilibrium between demand and supply

Figure 5.6: An activity system and transportation system shifts

Figure 5.7: The consumer surplus concept 


\section{CHAPTER 1}

\section{INTRODUCTION}

\section{$1.1 \quad$ Background}

Mobility of people and goods has a profound impact on a country's economic growth. Investment in transportation is therefore a critical component towards economic success and is recognized by developing countries at vital to economic development.

Many improvements in transportation technologies have been developed in response to the increasing demand for a safer, more reliable, and more effective transportation system. In this era of rapid technological growth, many emerging technologies are being applied to the transportation sector; and their timely implementation often proves very effective. For example, in the U.S., intelligent transportation system (ITS) technologies have been implemented to improve efficiency, safety, enforcement, and data base development.

Due to the numerous problems emanating from the environment and the competition on land uses; the strategy for improving transportation has changed in some ways from capital intensive to operational. Specifically, engineers are seeking to provide better transportation services by implementing relatively low-cost technological improvement plans rather than expanding the system physically. In this context, the application of technological advances, in particular telecommunications and information systems, has impacted all modes of transportation. The federal government alone has invested about one billion dollars in ITS research and operational tests over the past five years (U.S. DOT, May 1999). With significant funding from the private sector, as well as from state and local governments, ITS programs have become the single largest 
Department of Transportation (DOT) research programs this decade. (U.S. DOT, May 1999)

Understanding how a transportation system responds to the application of new technologies can help guide the decision-making process and will reduce uncertainties. The U.S. Department of Transportation is responsible for developing procedures to improve transportation systems, and predict future needs. The rapid change in technology has provided many new alternatives to improve transportation operations. Analysts must determine efficient combinations of technologies that yield high net benefits. Professional transportation systems analysts attempt to systematically analyze the choices available to public or private agencies when making changes in the transportation system (Larson, R., and Odoni, A 1997). Part of this task consists of predicting the changes in transportation systems resulting from the implementation of technology.

The technology investigated for the purpose of this study is ITS technologies, in particular, its application to commercial vehicle operations (CVO). ITS technologies apply topics such as information processing, communications, control, and electronics to improve enforcement and safety, administration, fleet and vehicle management, and highway traffic management (U.S. DOT, October 1996). See Figure 1.1 for various ITS/CVO Services.

Most ITS/CVO systems in use benefit the private and the public sector. Reduction in operating costs, increased productivity and efficiency, and eased compliance with regulatory agencies, are all positive effects to the private sector. As for the public sector, studies showed increased capabilities and efficiency for state agencies 


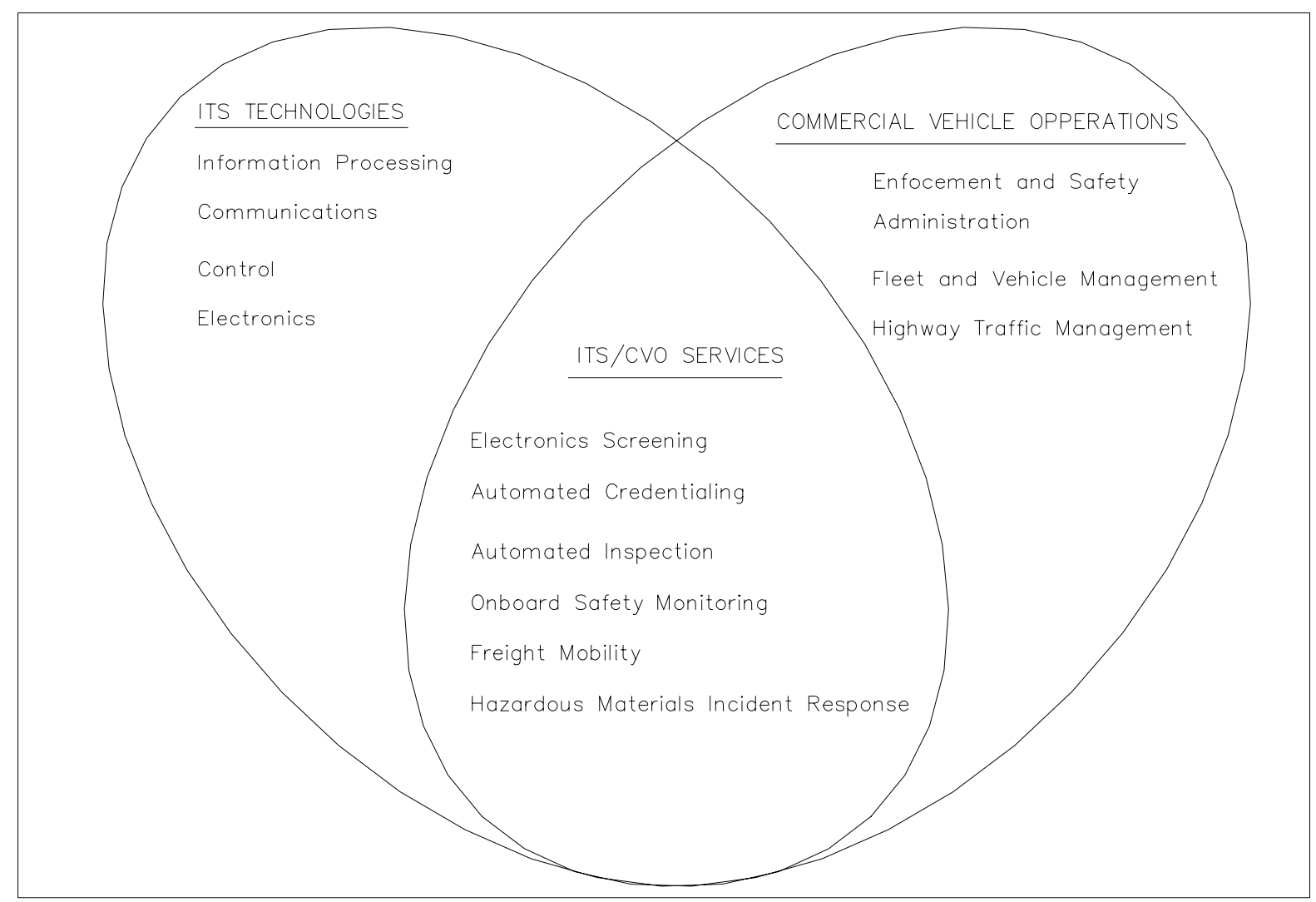

Figure 1.1: Common services between ITS and CVO technology

Developing countries characterized by rapid economic expansion and population growth are striving to improve transport. Motor vehicle fleets in developing countries are doubling every seven years, causing constraints on the system, environmental problems, and hindrance to economic growth (Cervero, R., Manson, J. Sept.1998). In addition, it is common for these countries to limit their planning issues to the project level. Problems in the transportation system are identified and met with little regards for system effects. 
Transportation management practices and technologies from advanced transportation systems might find relevance in developing countries in alleviating congestion. Unfortunately, technology's impact on the transportation system in a developing country remains a challenge. Little has been done in terms of a comprehensive activity-based way of analyzing a transportation system. Socioeconomic and sociopolitical for characteristics example have indirect, but substantial, impacts on the transportation system. Ignoring these issues in an analysis, especially in developing countries, will result in unrealistic predictions. In order to adequately incorporate socioeconomic and sociopolitical factors, policy makers need a broader framework when it comes to predicting how technology can impact the system.

In addition to the complexity involved in developing a comprehensive framework, the very context of transportation challenges remains qualitatively different in developing countries (Cervero, R., Manson, J. Sept.1998). In the U.S., the strategic implementation of ITS/CVO technology has become a relatively mature industry. Commitments and decisions have resulted in the implementation of various projects and applications. Whereas the ITS/CVO technologies and concepts in developing countries, are at the earliest stages of deployment. In addition, the predominant institutional differences compiled with geopolitics and socioeconomic issues, one cannot deduce that if new ITS technology proves effective in the U.S., the same technology would result in a successful implementation in a developing country. Which can present significant uncertainties in planning, implementation and outcomes of transportation investments.

For these reasons, a framework for predicting the impact of new technologies could prove helpful. A systematic approach towards including the pattern of social and 
economical activities in the prediction process is necessary. This will allow analysts to capture socioeconomic and geopolitical factors impacting the system, which in developing countries are dynamic in nature. It is useful to understand how these factors relate and interact to impact the transportation system. For the ultimate goals of quantifying benefits that transpire from improved transportation services usually associated with ITS/CVO technology.

\section{$1.3 \quad$ Objectives}

The objective of this study is to develop a framework for predicting the impact of new ITS/CVO technologies in developing countries. The procedure will be helpful to better predict future flow in the transportation system upon the deployment of ITS/CVO technology. The framework shall provide a basic set of principles and procedures on how to incorporate changes in the social and economical patterns when predicting future flows, and is expected to be helpful tool for policy makers faced with making investment decisions.

The task will be divided into three steps:

- The first step focuses on presenting prediction of flow volumes from a global perspective. This will specify and group the elements that interact to affect the flow in a transportation system. Transportation systems analysis must account for the complexity associated with social, political and economic forces that will affect the flow in a transportation system.

- The second section will present the concept of the procedural. Issues such as microeconomic theory, and consumer surplus are good and useful tools in transportation analysis. This allows for a consumer-based analysis to quantify 
benefits, needs and behaviors impacting the transportation system. This section will look at the factors affecting transportation supply and demand concepts, by developing basic function for each.

- The third section will focus on implementation. This section will devise a hypothetical case study dealing with the implementation of ITS/CVO in a developing country. This will specify the methodology and the data to be used for the analysis. The study will focus on freight transportation example in Lebanon, considering the trucking and maritime industry.

Predicting future flows will provide insights on how to maximize benefits and tackle problems early on. This will ameliorate the transportation system as a direct result of better decision-making processes.

\subsection{Summary of Chapters}

Chapter two is a Background on CVO. The literature found on ITS technology shows the various applications and their benefits in the transport world. On the administrative CVOs can benefit from concepts like the automation of ordering, billing taxing and control systems. The roadside level will focus on Fleet Control, Electronic Screening, and other important enforcement applications.

Chapter three is the Literature Review. Modeling how ITS will affect the system on the project level is well developed and lots of software packages can tackle the relevant issues involved. On the program level, little has been done in terms of developing activity-based analysis in predicting the impact of technology, a procedure 
especially useful for developing countries due to the more vulnerable nature of their transportation system.

Chapter Four is The Basic Structure of the Framework. This chapter presents the basic idea involved in developing a global framework. Predicting impact consists of predicting changes in flows. Both the activity system and the transportation system impact flow volumes. Their interdependencies and interrelationships will be modeled using the theory of microeconomic. The activity system is presented as demand, while transportation system as supply.

Chapter five is The Concept of the Framework. This chapter will focus on specific issues for both the activity and transportation system, and shows how a shift in either of them translates to changes in volumes or level of service. The concept of predicting a change in flow is presented in an analytical fashion. ITS/CVO technology impacts the transportation system causing a shift in the supply function. This shift indicates that more volumes can flow in the system and/or an improvement in the level of service. This in turn and over time will cause a shit in the activity system showing an increase in demand. The process is repeated and new improvement plans have to be considered and implemented.

Chapter six is the Implementation of the Framework. This chapter will test the framework by developing an example. Data will be used to establish demand and supply function for the country of Lebanon. A brief case study dealing with freight mobility will be presented. The focus will be on predicting the impact of implementing ITS/CVO technology on a specific multimodal-shipping route involving a port in the city of Beirut, international roads crossing the Lebanese border, and the local area network. The 
analysis will attempt to quantify the benefits in an effort to choose the best improvement alternative.

Chapter seven is the Conclusions and Recommendations. In this chapter the conclusions of the study are discussed and future recommendations are presented. The study shows that there is a potential benefit for using such a framework. The problems facing this kind of activity-based framework are the data. There needs to be good data collection schemes to better predict future flows. 


\section{CHAPTER 2}

\section{BACKGROUND ON COMMERCIAL VEHICLE OPERATIONS}

The background concentrates on the various applications of ITS technology to transport, in particular its application to Commercial Vehicle Operations (CVO). The applications of ITS are those which have a high time-value of information. For example, in emergency vehicle response, if an emergency crew does not receive the information in a timely fashion, the value of that information is reduced dramatically. Fleet operators and managers work with a system that have very high time-value and require real time data to run a smooth operation.

\section{$2.1 \quad$ ITS Technologies}

ITS technology offers a promising way of making better use of existing infrastructure through the application of communication systems and computer technologies to transportation. For developing countries, one can find many applications for ITS technologies. For the purpose of this paper, emphasis will be on the application of ITS technologies to improve Commercial Vehicle Operation (CVO) applications.

A country's economy relies on the timely and reliable movement of goods. CVOs are categorized according to the FHWA into commercial vehicles, public service vehicles, and passenger vehicles and are designed to enhance freight mobility. Improved safety, reduced congestion, improved mobility, reduced environmental impact, improved energy efficiency, and improved economic productivity, are all results of successful implementation of ITS/CVO technology. 
The breakdown of the technology investigated for the purpose of this study is outlined below, (Intelligent Vehicle Highway Society of America, 1992) and categorized in terms of the type of services they provide.

1. Automated credentialing

- Electronic Credentials (EC) -permits, registration, and all required licenses can be obtained and paid for electronically. Motor carriers can file their requests electronically, and electronic record of the credentials requested (and paid for) could be sent to the motor carrier's headquarters or other desired location.

- Automatic Vehicle Classification (AVC) - Provides electronic record of vehicle type and contents. Employs EC technology to identify vehicle status based on registration information in a central database.

2. Freight mobility, management and control

Automated Vehicle Location (AVL) - Provides real-time information on the location and status of vehicles by employing Global Positioning System (GPS).

- Electronic logbook - Electronic beacons placed at strategic locations enable motor carriers to replace the manual trip log with an electronic procedure. The number of vehicle-miles and the appropriate taxes could be recorded electronically.

- Two-Way real-time Communications (TWC) and Advanced fleet managementEmploys Advanced Traveler Information System (ATIS) and Advanced Traffic Management systems (ATMS) to provide real time information to drivers or dispatchers concerning traffic congestion, incidents, and routing alternatives. 
Advanced vehicle routing algorithms and real time congestion information allow for dynamic network management. Refer to Figure 2.2 for further details.

3. Onboard safety monitoring

- Driver/vehicle real-time safety monitoring - provides records of duty logs, and information on commercial driver's license. Vehicle-related elements could include operational data and conditional information such as status of brakes, oil pressure, lights, tires, and steering.

4. Automated inspection

- Weigh in Motion (WIM) - allows for commercial vehicles to bypass weigh station by weighing the vehicle while in motion. Vehicles equipped with a special transponder are weighed electronically by in-pavement scales and readers. Refer to Figure 2.3

- Automated Vehicle Classification/Identification (AVC/AVI) Provide uninterrupted movement of commercial vehicles. Inspection or weighing stations can be bypassed if the vehicle is in compliance with the proper laws and regulations. If a vehicle is not in compliance, it can be flagged down for inspection. AVI systems have the ability to monitor vehicles from origin to destination by integrating present surveillance systems. Other AVI applications include fleet control and surveillance, and access control. (Bernstein. D., Kanaan. A., 1993)

5. Electronic screening

- Automated (electronic) toll collection - Employs automated credential-checking technology or AVI. Tolls are paid electronically to allow for uninterrupted operation. 
- License Plate Recognition System (LPR) -Employs image recognition technology to scan and store license plate numbers in a database. This provides law enforcement with real time information to flag a vehicle for inspection or can be done via a variable message sign to flag a vehicle to a static weight scale (Olberding, J.C, 1999) Refer to Figure 2.1.

\section{Hazardous material incident response}

- Hazardous material information systems - In emergency situations, incident management response teams and enforcement authorities can obtain timely, accurate information on cargo contents, enabling them to react quickly and properly.

Other technological trends are apparent across the transportation system. The efficient and cost-effective transport of freight requires moving containers from one mode to another - particularly between ships and trucks - and the proper coordination of these operations. Automation technologies are increasingly being used to help manage and track this process. Examples of this approach include transmitting shipping documents by Electronic Data Interchange (EDI) and tracking cargo by automatic equipment identification (AEI) systems. In addition, the explosive growth of business use of the Internet is allowing carriers to offer customers an inside look into the real-time processing of their orders.

The benefits of the above-mentioned technologies allow fleet managers to obtain accurate and real-time information, monitor vehicles in the field, maximize equipment utilization, track shipments more effectively, and reduce rehandles, claims, delays, and overhead (TRB 1992). 


\subsection{Potential Benefits of CVO}

Applying technology to a competitive transportation market such as the commercial vehicle industry will benefit all parties involved such as operators, consumers, and carriers (U.S. DOT 1999). The benefits are presented below:

Congestion reduction:

- Reduced congestion level and congestion costs

- Increased vehicle occupancy rates and Increased volume of goods

- Reduced delay of a vehicle and variance in travel time on a given route

- Reduced excess travel caused by navigational problems and more accurate prediction of travel times

Higher Quality Mobility

- Increased range of traveler destinations and routes

- Increased use of alternative transportation routes avoiding residential roads

- Decreased travel times and decreased travel distances

- Increased travel time predictability

- Reduced injuries, and accidents

- More effective law enforcement

Environmental Issues

- Reduced energy consumption

- Decreased air pollution and noise pollution

\section{Energy Efficiency}

- Reduced energy consumption

- Improve information regarding public transportation alternatives 
- Improve responsiveness of public transportation to traveler requirements

- Improve information about travel links

Improved Economic Activities

- Reduced new road construction costs

- Improved efficiency of roadway operations and traffic management

- Improved efficiency in public service vehicle operations.

- Improved efficiency of carriers and shippers

- Reduced private vehicle operating costs

Economic Productivity

- Decreased vehicle operation costs

- Increased vehicle service coverage and efficiency of dispatch operations

- Improved timeliness of delivery

- Improved vehicle maintenance costs

There is some information gaps in the literature concerning the actual benefit of an ITS/CVO system. There is a lack of a comprehensive state-by-state survey of potential deployment and their related costs and benefits especially to public agencies. The Budgetary Implications of ITS/CVO for State Agencies was commissioned by the Federal Highway Administration (FHWA) to address this gap. The report investigated several ITC/CVO programs already in place in the U.S. Table 2.1, shows some relevant ITS/CVO project and briefly summarizes their relevance. 


\begin{tabular}{|c|c|c|c|c|}
\hline Title and Date & $\begin{array}{l}\text { Publishing } \\
\text { Org./Author } \\
\text { And region }\end{array}$ & $\begin{array}{c}\text { Effects } \\
\text { Addressed }\end{array}$ & Tech. Studied & Summary \\
\hline $\begin{array}{l}\text { PrePass Project } \\
\text { Overview for } \\
\text { automated Weight } \\
\text { Station Pre- } \\
\text { clearance } 1995 \\
\end{array}$ & \begin{tabular}{|l|} 
Heavy Vehicle \\
License Plate, Inc. \\
National
\end{tabular} & \begin{tabular}{|l|} 
Indirect \\
Benefits
\end{tabular} & $\begin{array}{l}\text { Weight Station } \\
\text { Clearance }\end{array}$ & $\begin{array}{l}\text { This study is a discussion } \\
\text { of the indirect benefits on } \\
\text { ITS/CVO deployment. }\end{array}$ \\
\hline \begin{tabular}{|l|} 
ITS Trends in \\
Freight Management \\
and CVO \\
Applications 1995
\end{tabular} & \begin{tabular}{|l|} 
Brown, Santeiu \\
(Amtech Systems \\
Corporation \\
National
\end{tabular} & \begin{tabular}{|l|} 
Direct \\
private \\
benefits
\end{tabular} & \begin{tabular}{|l|} 
Vehicle \\
roadside \\
Communications
\end{tabular} & $\begin{array}{l}\text { This study describes new } \\
\text { technology and } \\
\text { recognizes widespread } \\
\text { compatibility as the } \\
\text { primary obstacle to cost- } \\
\text { effective implementation. }\end{array}$ \\
\hline \begin{tabular}{|l|} 
Institutional issues \\
Related to the \\
Application of \\
Intelligent Vehicle- \\
Highway Systems \\
Technologies to \\
Commercial Vehicle \\
Operations in \\
Indiana. 1994 \\
\end{tabular} & \begin{tabular}{|l|} 
Kavalaris, Sinha \\
(Joint Highway \\
Research Project) \\
Indiana
\end{tabular} & \begin{tabular}{|l|} 
Direct state \\
agency \\
benefits
\end{tabular} & $\begin{array}{l}\text { General } \\
\text { ITS/CVO } \\
\text { Technology }\end{array}$ & $\begin{array}{l}\text { This is the most full } \\
\text { discussion of the direct } \\
\text { agency benefits, } \\
\text { increased enforcement } \\
\text { revenues, and } \\
\text { penetration rates. }\end{array}$ \\
\hline \begin{tabular}{|l|} 
Overcoming \\
Institutional Barriers: \\
Recommendation \\
Actions.1994
\end{tabular} & $\begin{array}{l}\text { Booz-Allen and } \\
\text { Hamilton Inc. } \\
\text { Colorado }\end{array}$ & \begin{tabular}{|l} 
Institutional \\
Barriers
\end{tabular} & \begin{tabular}{|l} 
General \\
ITS/CVO \\
Technology
\end{tabular} & $\begin{array}{l}\text { This Study identifies the } \\
\text { institutional barriers to } \\
\text { ITS/CVO implementation } \\
\text { and develops a plan of } \\
\text { implementation sensitive } \\
\text { to those barriers. }\end{array}$ \\
\hline \begin{tabular}{|l|} 
Dakotas' ITS/CVO \\
Institutional Issues \\
Study. 1996
\end{tabular} & \begin{tabular}{|l|} 
Smadi, Rodriguez \\
(Upper Greater \\
Plains \\
Transportation \\
Institute, North \\
Dakota State \\
University) \\
Dakotas
\end{tabular} & $\begin{array}{l}\text { Direct state } \\
\text { benefits. }\end{array}$ & \begin{tabular}{|l} 
General \\
ITS/CVO \\
Technology
\end{tabular} & $\begin{array}{l}\text { This study finds that the } \\
\text { costs of deployment of } \\
\text { ITS/CVO will be greater } \\
\text { than any other costs } \\
\text { involved }\end{array}$ \\
\hline \begin{tabular}{|l} 
Trucking Scan, \\
Automating and \\
Improving Roadside \\
Checking.1996 \\
\end{tabular} & \begin{tabular}{|l} 
Reid, Myers \\
(Telstra Applied \\
Technologies) \\
National \\
\end{tabular} & $\begin{array}{l}\text { New } \\
\text { technology }\end{array}$ & Weigh-in-Motion & $\begin{array}{l}\text { This study describes a } \\
\text { new technology that } \\
\text { tracks vehicles in motion. }\end{array}$ \\
\hline
\end{tabular}

Table 2.1: Relevant ITS/VCO projects investigated

Source: Budgetary Implication of ITS/CVO for State Agencies. FHWA 1998 


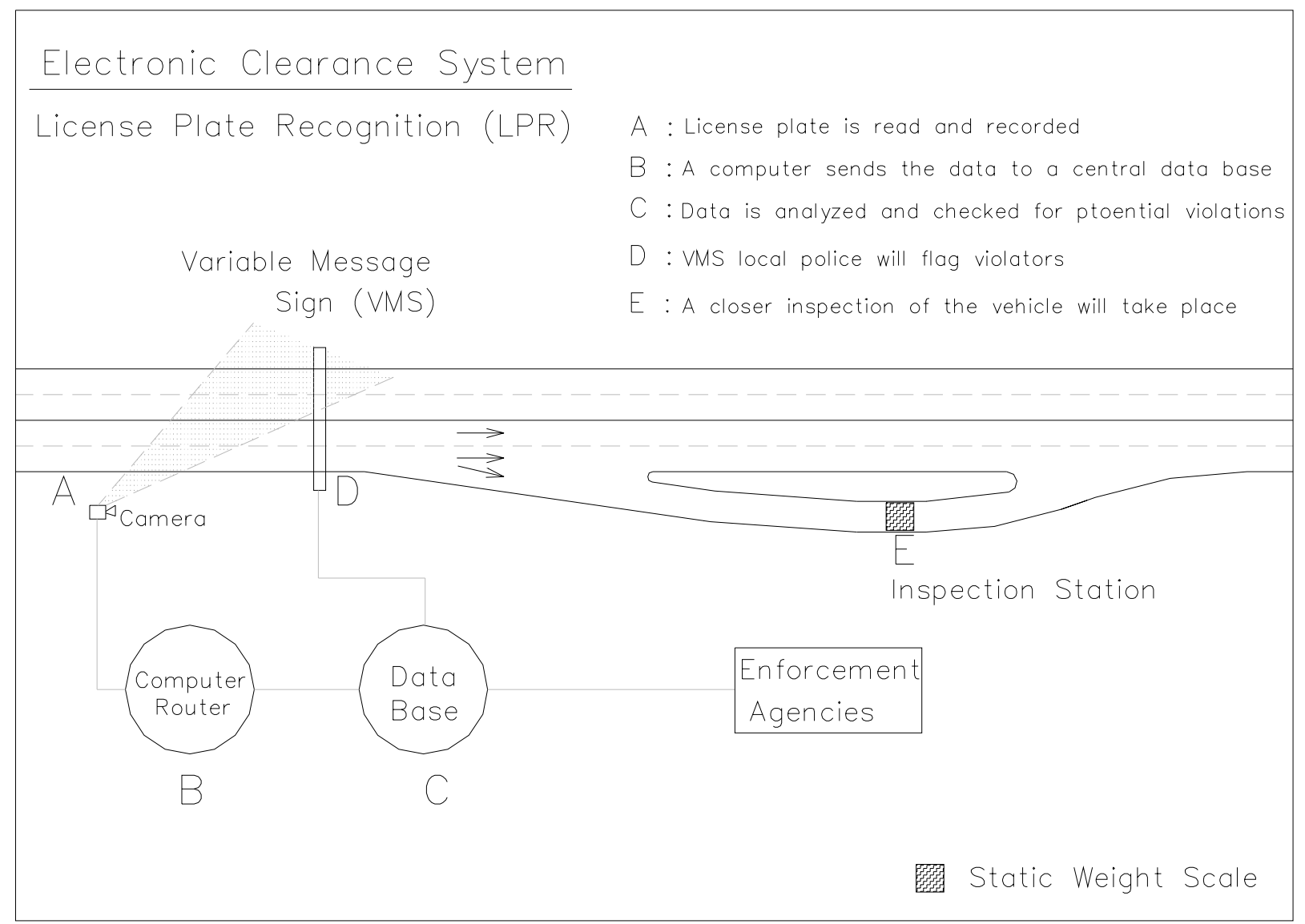

Figure 2.1: The License Plate Recognition System (LPR) 


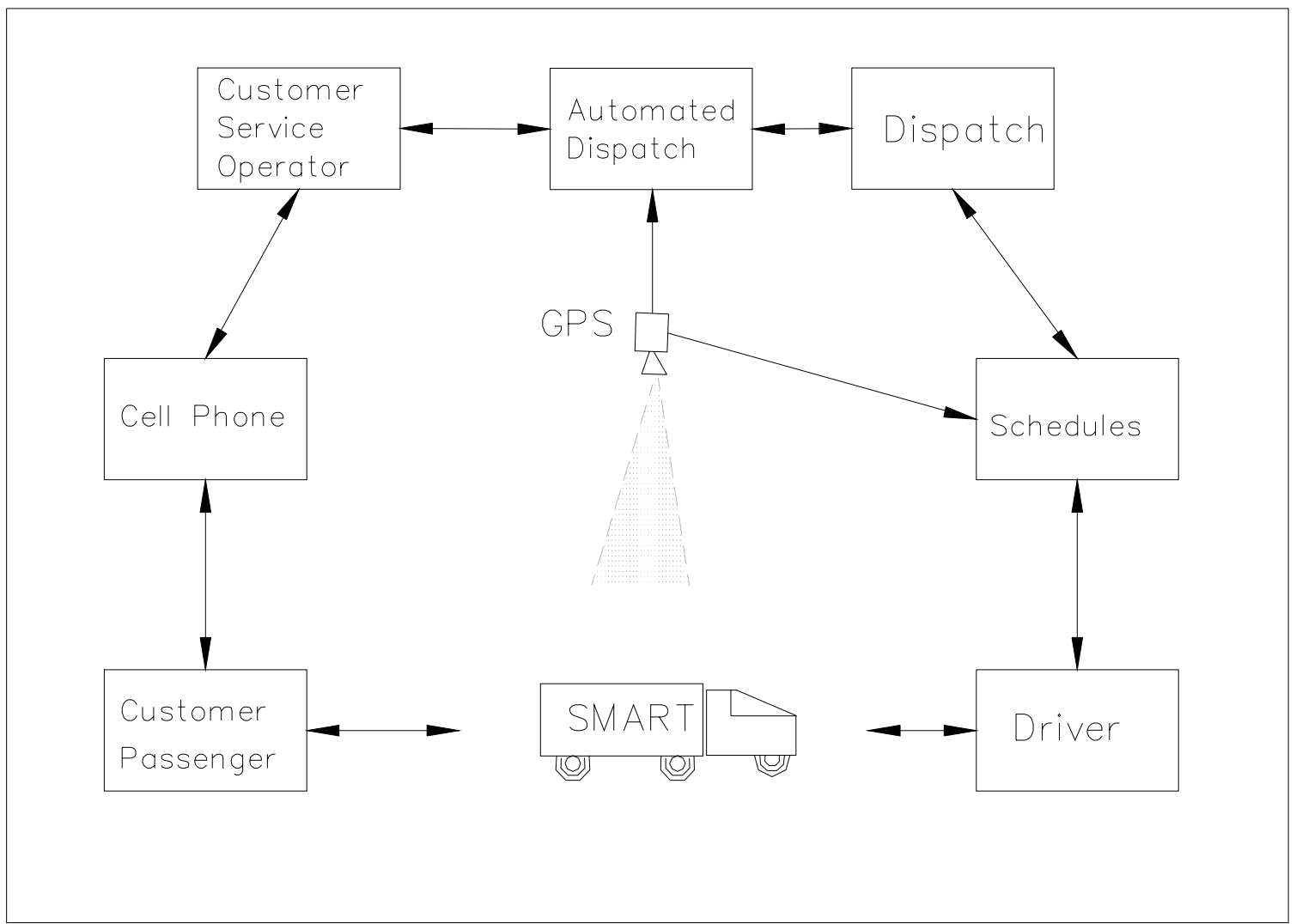

Figure 2.2 Figure showing the Advanced Vehicle Routing System 


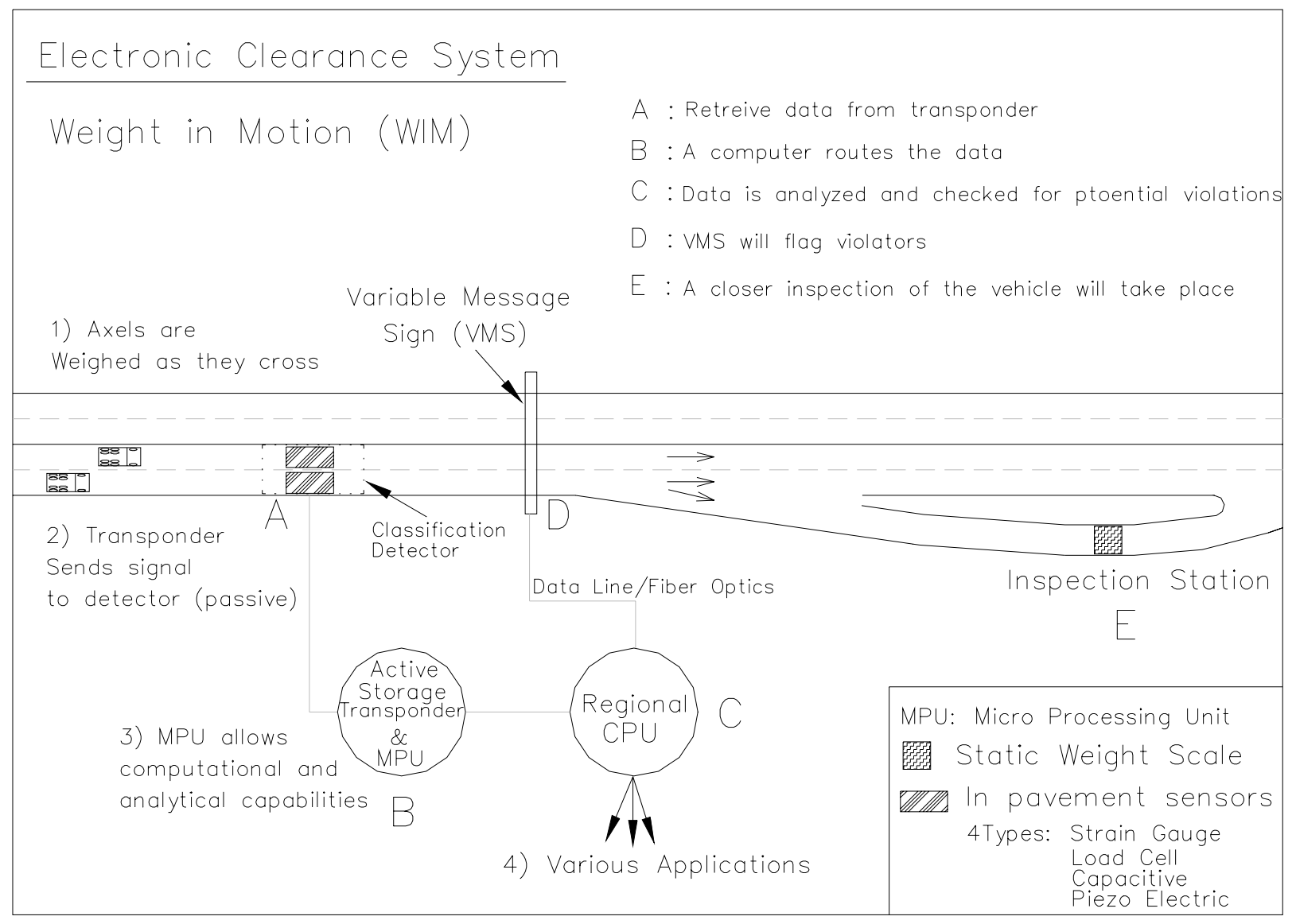

Figure 2.3 The Weigh in Motion (WIM) System 


\section{CHAPTER 3}

\section{LITERATURE REVIEW}

This chapter highlights the key issues and important findings for the topics of transportation planning and operation, and economic principles. In addition, the literature reviewed is classified, and the rationale behind the search process is explained.

\subsection{Introduction}

The literature review conducted for this study, ranges from very early classical transportation analysis concepts developed in the late sixties to the latest material found on transportation planning and operation. Textbooks, journals, reports, articles, research projects, and case studies are the types of material reviewed, of which some where found on the Internet. The main topics reviewed are fundamentals of transportation system analysis, transportation planning and operation in particular economic principles.

The idea of this study is to widen the scope of transportation technology impact assessment beyond the traditional project level demand forecasting. The analysis is defined to include all aspects of the decision making process in transportation improvement. The text used for this study provided knowledge on the fundamentals of transportation analysis.

The journals and articles reviewed for this study highlight the latest methods used to improve CVOs. The Federal Highway Administration is an example of a public entity that will benefit from the implementation of ITS/CVO. Carriers and shippers are examples of private entities benefiting from this technology as discussed in Chapter 2. 
The new material on transportation planning primarily involves the unique role of transportation in urban development, economic growth, social equity, and environmental preservation. In addition, research papers published by the Transportation Research Record (TRR), provide a better understanding of freight movement and the impact of technology on the transportation system including project level operation and planning procedures related to CVOs.

The material found on transportation systems in developing countries ranges from textbooks, university research projects, and annual economic reports. The purpose is to assess the extent to which the scholarly literature addresses the impacts of technology on the transportation system in a manner suitable to be applied to developing countries.

\subsection{The Scope of Literature Used}

The newer material found on transportation planning deals mostly with urban transportation improvement alternatives. This material shows that modeling ITS impacts at the project level is well developed with an abundance of software packages available. For example, making use of the Four Step method and optimization techniques. Since the use of ITS technology for CVOs in developing countries is nearly nonexistent, this material has little to offer when used in the context of a developing country.

Introducing such technologies into an underdeveloped country requires strategic level decision-making, through a global outlook on transportation. Unfortunately, the demand forecasting methods such as the traditional four-step process method are useful for project level formulation but have little to offer on strategic decision making. 
The rational for the literature used is split into three parts, the first part is accomplished by presenting the work of Manheim. Manheim's, Fundamentals of Transportation System Analysis $\{1979\}$ present theories, classical concepts, and methods underlying prediction. The actors that intervene to impact flow in the system are viewed from a global perspective.

The second task involves narrowing the literature from fundamental to a conceptual stage. In Wohl and Hendrickson's, Transportation Investment and Pricing Principles: An Introduction for Engineers, Planners and Economists 1984, economic principles are applied to develop methods and techniques to identify the desirability of different policy actions. On one hand, their work offers a more suitable way of quantifying benefits accrued to the system than Manheim's. On the other hand, Manheim's work offers a more general level.

The sections below will focus on Manheim's work as well as Wohl and Hendrickson, and will explore if a relation could be established between both concepts. Combining these two concepts will allow for the universality that Manheim's work provides and the applicability that Wohl and Hendrickson offer in theirs.

\subsubsection{Transportation Economics}

Economic principles, when applied to transportation analysis can allow for a more global approach to observe, understand, and evaluate transportation systems. When analyzing a network, data for each link, and each activity on each link has to be recorded and analyzed. 
Manheim Fundamentals of Transportation System Analysis 1979, provides the basic introduction to transportation system analysis. The subject is treated as a coherent field of study and can be applied to all transportation system applications. The challenge to transportation systems analysis according to Manheim is to delicately and deliberately intervene in the complex fabric of a society to use transportation effectively, in coordinating the public and private sector to achieve the goals of that society.

The fundamental principle of the approach is to understand the interrelation between the Activity System and the Transportation System. The Transportation System is considered a subsystem of physical elements, while the Activity System is the complex socioeconomic and sociopolitical forces of society.

Manheim defines the Activity System, as the social, economical and political activities taking place over space and time that will affect the flow pattern. Later chapters will develop a framework specialized for CVO applications. The Transportation System is regarded as the general characteristics identifying the coverage, the physical condition, and the capacity of the system.

The basic theory for the interrelation of the Activity System and the Transportation System must be understood in order to attempt to model it. Figure 3.1 illustrates how these two subsystems interact to produce a flow pattern. The relationships are of three types and are defined below:

- Type 1 relationship: Travel Market Equilibrium. Both the transportation system and the activity system interact to determine the flow pattern in the transportation network. 
- Type 2 relationship: Activity System Equilibrium. The current flow coupled with changes in levels of service and exogenous events occurring over time will cause changes over time in the Activity System. The long-terms interactions between the Transportation System and the Activity System are modeled to simulate the evolution.

- Type 3 relationship: Operator Equilibrium. As a result of the flow pattern, operators will react, resulting in changes in the transportation system, or modification of existing services.

Wohl and Hendrickson's work is aimed at improving the analysis of transportation systems. The main goal is to develop methods and techniques to identify the desirability of different policy actions.

First, Wohl and Hendrickson identify all aspects of the system that are of concern. Second they develop a framework to be used for the predicting the benefits and costs of different alternatives. Third, they identify the way benefits and costs relationships behave. Changes might occur in demand as capacity changes and different options are introduced. Fourth, they identify the methods used to assess the worthiness of different alternatives allowing the process to assess multiple objectives.

One must pay close attention to developing travel demand, benefit, and revenue functions because benefits are hard to estimate. Operational tests have proved to be a good source of data. Unfortunately, the operational tests are designed to evaluate the capabilities of new technologies. They are not designed with benefit estimation in mind, and do not provide cost savings associated with the whole transportation system, which may result in higher margins of error for benefits analysis. 
Transportation facilities are capacity constrained, user travel times increase as greater volumes use the facilities (Wohl 1984). Thus vehicles on a roadway tend to interfere with one another causing traffic to slow down. Each driver will endure increased travel times, delays, and effort for making a trip.

Every shipment under different conditions of price and service has a value or gives benefit to the shipper or to the user. The value of the trip or the benefit to the user gives rise to demand. Travel demand is dependent on the price, service, destination characteristics, and attributes of potential trip making. Travel demand can be defined as the measure of the travel benefit or to make a trip under a particular set of circumstances.

Microeconomic theory will be used to further develop the framework to capture equilibrium between the Transportation Systems through performance functions and Activity System through a demand function. The basic concept underlying market equilibrium requires special considerations when applied to transportation. From the demand side, each traveler can choose from a number of different links to travel from origin to destination. The choices of the each traveler will be based on a perceived perception of levels of service associated with each link. At the same time, the level of service will be influenced by the choices since performance is dependent on the number of users that are using the capacity. This suggests that demand for all origin-destination pairs in the network should be considered (Fernandez and Friesz 1983). On the supply side, aspects of the transportation system that affect capacity have to be considered. A supply function relates the volume of travel, on a particular link, to cost of travel or level of service. However, the path of a typical trip will consist of multiple networked links, hence data of all links involved have to be modeled. The service should incorporate as 
many elements of the system as possible, such as technology, goods, vehicles, resources, cost and the interdependencies of their relationship.

The potential inconsistencies among the travel demand component estimates will translate into inconsistent results. Assessing components of the Activity System provides insight on transportation demand. The complexity of these procedures and the enormous amount of data required for this type of analysis justify the use of the travel market equilibrium analysis based on the Manheim concept of Activity and Transportation Systems.

\subsubsection{Transportation Planning and Operations}

The planning and operation section indicates the relevant issues to be considered to focus on technology and CVOs. Kanafani's work is aimed at developing analysis techniques for the application of new technologies.

In "Urban Transportation Demand Analysis" potential traffic is differentiated from traffic flow. Both represent traffic volumes in the form of vehicles, passengers, goods, or people. Traffic flow is a single measurement of the actual flow on a facility, which can be misleading when trying to understand the need for transportation. Potential traffic is a much better measure of the actual need for transportation since it takes into account the additional traffic that might flow, if additional capacity is provided.

For this reason, transportation demand analysis, concentrates on the study of the socioeconomic activities that generate demand for transportation. Quantifying the behavioral aspect in transportation demand will be very useful in trying to analyze

demand. The ability to quantify aspects of demand will help in resource allocation that 
currently defies explicit solutions. The aspect that makes demand analysis a tedious process is the fact that randomness exists, even if the consumer makes the same decisions repeatedly.

Kanafani defines the activity demand set as the set containing all urban activities that an individual would have a demand for and depends on the socioeconomic characteristics. Not all activities are considered. Available activities that can be quantified in terms of distance or cost are the activities used.

The activity supply set is defined as the "set that includes, for each potential traveler, the totality of urban activities available at different transportation costs" (Kanafani 1983). It is of course not infinite, but is made to consider all activities within the domain of the urban traveler, that will probably enter the choice process.

Demand analysis relates behavioral assumptions to the process choice. It is usually understood that the urban traveler faces a succession of choices regarding the urban activities and related travel (Kanafani 1983).

The consumer demand theory looks at understanding the behavior of an individual making decisions about the activity to be undertaken. For the purpose of developing a demand function, the following should be examined:

How consumers/shipper of goods may differ in behavior?

How socioeconomic activities may affect consumer behavior?

How will changes in the transportation system affect the choices of the consumer?

"The constant travel time budget is one of the few behavioral paradigms to be developed into an operational model system" (Shunk 1991). A theoretical approach to travel demand presents this concept of the constant travel time budget. A fixed amount 
of time exists that travelers would like to spend traveling. If capacity on a certain facility is improved and cost is reduced, travelers will use the time saved on that trip to make another trip. This paradigm generates counter-intuitive results. Another example would be to reduce cost of travel. The money saved on a trip will be used on another trip. It is the same paradoxes derived from the constant travel budget paradigm, and it is one of the issues that should be researched. These issues make it essential to analyze the demand and show that demand is different than the actual flow.

In summary, the prediction process must consider all aspects of a global complex transportation system, and activity system focusing on understanding their interrelations and interdependencies. In developing countries, especially, socioeconomic and sociopolitical issues are dynamic in nature and hard to foresee. The changes will impact the demand and the supply of a transportation system, causing it to react and behave in predictable and unpredictable manners. 


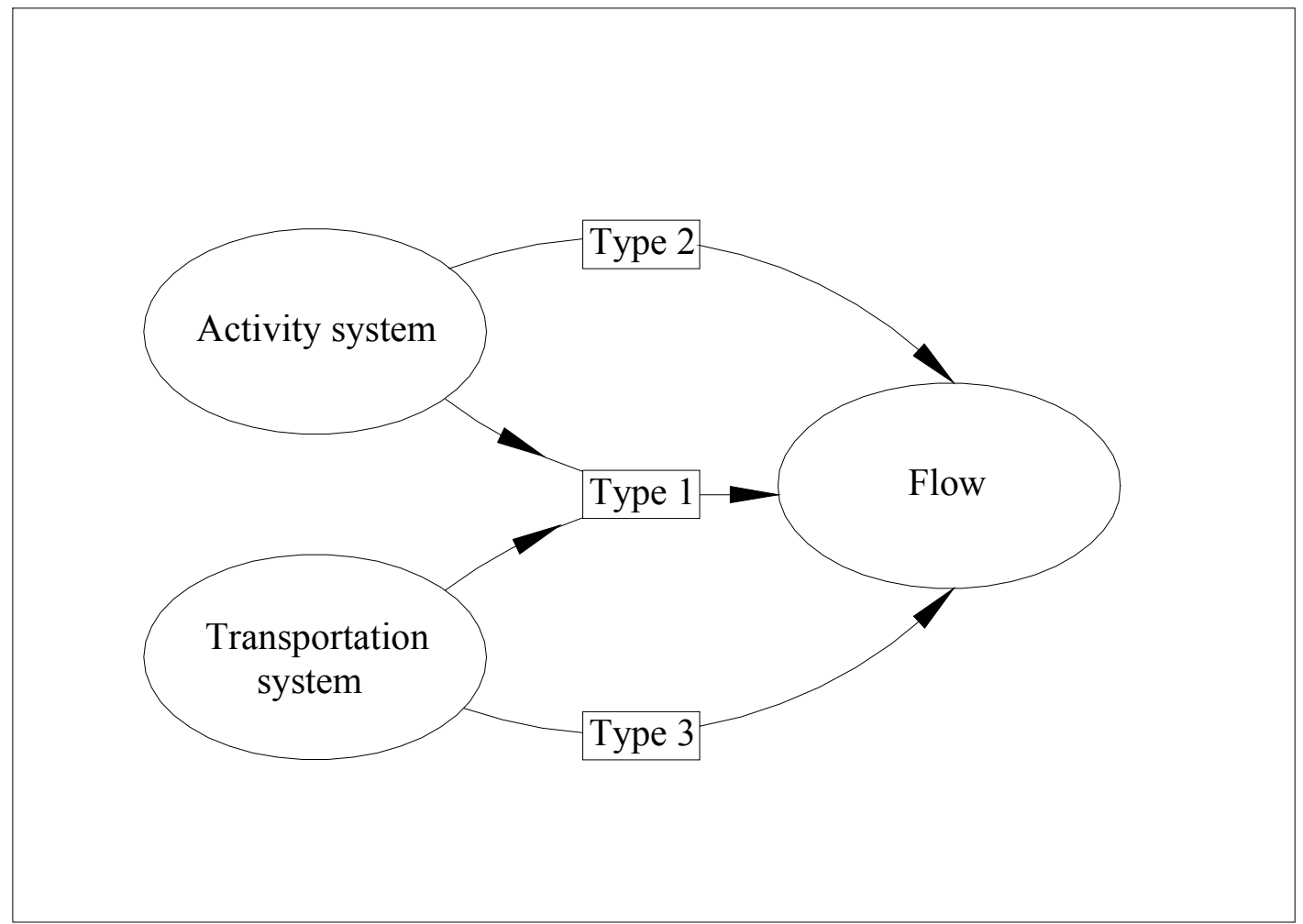

Figure 3.1: The basic relations between the Activity system, the Transportation system, and the Flow (Manheim 1969) 


\section{CHAPTER 4}

\section{GLOBAL LEVEL FORMULATION}

This chapter identifies the fundamentals of the framework. The components that will interact to determine the flow volumes in a transportation system will be divided into the activity system and the transportation system. To limit the issues involved in a global framework, the study will focus on commercial vehicle operations.

\subsection{Introduction}

Because developing countries are still early in the process of technological improvements, decision-makers have little to go on in terms of understanding how technologies can impact a system. Identifying the fundamentals of the framework will tackle issues on the global level and help make it more adaptable. The general approach to the framework will follow Manheim's classical concept, and will be more specific to CVO. The general configuration of the system is shown in Figure 4.1 and has three basic components.

The first component of the framework highlights the general options intervening in the transportation system. Manheim defines options as "Those aspects of the transportation and activity system that can be directly changed by the decisions of or on several individuals or institutions".

The relationship between the transportation system and the activity system is complex and dynamic in nature. Understanding the interrelationship between the variables that influence the transportation system will improve the prediction of flow 
volumes. The options dealing with the activity system will be looked at separately, from those dealing with the transportation system. Both have a direct impact on the flow.

The second component is the model formulation. The basic idea is to represent the transportation system as a supply model and the activity system as a demand model. The goal is to show how to establish travel market equilibrium for the ultimate goal of quantifying benefits. The focus will be on the Type one relationship; refer Figure 3.1.

The third component of the framework highlights the impact. Predicting the effects of changes in the transportation system reflects changes in travel patterns (flow). Predicting impacts of several alternative options will require the evaluation of impact on all groups involved. A change in the transportation system can impact several groups making it essential to balance interests between groups.

\subsection{Options Intervening to Impact the Flow Volumes.}

The options shall be divided into the Transportation Systems Options and the Activity System Options. The Transportation System options capture the full scope of the transportation plans and policies and the Activity System options captures the social / economical activity. Therefore identifying the elements that will affect CVOs will be essential to model demand and supply.

\subsubsection{The Transportation System Options}

The Transportation System Options are those decision variables affecting the service offered by transportation and can directly be changed or manipulated to improve the system. The transportation system consumes resources to offer a service. If the 
resources consumed exceed the benefits provided, changes have to be made. Services provided by the Transportation System include time of travel, road condition, volume of goods etc. The recourses consumed include land, labor, environment, and direct costs. As shown in Figure 4.1, these variables influence the supply side of the system. The spectrum of options is categorized as follows.

a) Technology: The options regarding ITS technology assist all users of the system in the transfer of information. Managers of the transportation system, freight vehicle drivers, operators, shippers, government and customers will all benefit from the increased efficiencies associated with a multi-faceted communication. Congestion avoidance, real time monitoring, better route guidance, enhanced enforcement and more accurate data collection for future research are associated with ITS/CVO technology.

b) The General configuration of the Network: This option defines the CVO network and identifies its general configuration and location. The representation of the network is done through nodes and links. For the purpose of this study, the flow on the links will be assumed as unrestricted flow. As for the nodes, a subnetwork of links within the node will help determine properties of that node. This study does not look at the sub-network within the node. An assumption will have to be made regarding the behavior of these nodes. Nodes are key components in the transportation chain. Having a smooth operation at nodes will result in uninterrupted transfer of goods. The physical condition of the network has to be investigated as well. 
c) Link Characteristics: The network consists of a series of routes, making it imperative to investigate link characteristics. The goods moved naturally will define the modes and vehicles involved in transportation. Usually the transportation of goods requires the use of more than one mode and more than one link. Link characteristics have to be identified in terms of capacity, geometric design, safety, and physical condition.

d) Operational and organizational policies: include operation management, organizational, and institutional decisions. For instance, ITS technologies and networks typically cut across geographical and jurisdiction boundaries and therefore coordination and specific institutional and political agreements will be needed. It will be important to establish common and compatible technology to be adopted across the borders. Policy and guideline committees to properly coordinate the implementation of ITS concepts will need institutional maturity. Since the institutional "culture" in developing countries is still immature, ITS applications are likely to pose certain problems due to several issues. i) The lack of skilled personnel to maintain and operate this technology. ii) The lack of an organized network usually associated with a third world country. Which pose problems in managing and operating the transportation system. iii) Data is usually incomplete and in some cases irrelevant.

\subsubsection{The Activity System Options}

The options belonging to the activity system are the ones related to transportation demand. Demand focuses on system needs generated from the activity levels of 
passengers or freight and their spatial distribution. The activity System Options captures the social, economic, political activities taking place. These options are hard to control, none the less they have to be included in the analysis process since they have an impact on demand. The options considered are as follows:

a) The socioeconomic factors that have an effect on freight activity are population growth, per capita income, economic growth, spatial migration, and trade. Using these indicators one can define a relationship between the socioeconomic variables to demand volume.

b) Geopolitics: Political issues in third world countries are very different in nature if compared to the core countries. Political decisions in the U.S. for example might set environmental mandates or enforce new laws and regulations. While politics in a country from the third world might involve a political / economical embargo which, if lifted, will generate a dramatic increase in transportation demand.

c) User characteristics: User behavior is highly dependent on the perception of a certain service provided. Shippers are concerned in making decisions on shipment size, density, bulk, and containerization alternatives. This will have an affect on trip demand and may alter the uses of modes.

\subsection{Supply and Demand Models}

The transportation supply model uses level of service as a surrogate for the Transportation System options. The function defines the relationship between the quantity and "price." The relationship is such that if the volume on a facility increases the price of travel will increases subsequently declining the level of service. Naturally 
the adverse is true, if the volume decreases (or capacity increases) on a facility, the level of service increases, and travel costs are reduced.

The demand function is generated from the activity system. The demand function measures the willingness to ship and defines a relationship between quantity and price. In such that, if the quantity increases, the price for making a trip or shipping goods decreases and the service level is improved.

In order to develop a methodology for analysis, one needs to understand the way in which demand for transportation arises. Transportation behavior is subject to many uncertainties and unknowns. In the case CVO in a typical urban setting, one consumer from a shipper will have to make decisions about when to ship the goods, the frequency of the shipments, and which mode or route to use. The combination of these choices will result in an enormous number of choices open to the shipper.

Demand can be defined as the potential for flow of traffic, goods or people. It is important to note that the potential for flow is not the same as the existing flow. The following example will help clarify the fundamental difference. Consider two towns A and $\mathrm{B}$ linked by a two-lane dual carriageway. Town $\mathrm{A}$ is an agricultural town with a surplus of food products is being generated. Town B is a mining town with no food production capabilities. Traffic flowing from town A to B carries food products for the mining population living in town $\mathrm{B}$. If we consider a scenario that town $\mathrm{B}$ discovered a new mining field expecting to increase the population by $50 \%$. More food is going to be needed, increasing the demand on the link between the two towns. If the highway facility is not upgraded, the cost to transport goods will be higher because the highway will be operating at lower LOS. The volume increase on the facility will not represent the 
demand because we are not accounting for additional traffic that might flow into the facility if capacity is increased.

The measure of demand becomes the difference in the flow volume at different LOS. It can be seen from this example that measuring transportation demand is much more complex than just measuring the increase in volume. "Transportation demand analysis is the process of relating the demand for transportation to the socioeconomic activities that generate it." The demand between A, and B is called a derived demand, since it is dependent on the need of foodstuff in town B.

\subsection{Impact on Different Groups}

The framework defines the impact on various groups involved. The impact will vary from one group to another. When considering improvement alternatives, some groups may benefit while some may lose. It is important to achieve the right balance of benefits between all groups involved. The impacts are categorized into the following:

The Consumer Impact: The impact on the traveler, or a shipper of goods. Differentiating the user by the location within the region, the trip purpose, and the socioeconomic group. The user might be faced with different services. This might be the choice between a non-stop service, and multi-stop, between a 3-hour waiting time and a 5-hour waiting time. The user looks at the system in a disaggregated perspective; the concern of the user is to have many options to choose from with relatively appropriate service offered.

The Operator Impact: Operators of transportation facilities, For example: port authority, highway maintenance agencies, or inspectors. The operator looks at the system 
in aggregate perspective. Profitability is primary the concern of the operators, i.e. what are the revenues and the costs of the strategies implemented?

The Physical Impact: The impact from the physical presence of a transportation facility on different groups. The groups are differentiated by type of impact. Family displacement, job opportunities, environmental degradation, and land use impact.

The Functional Impact: The Impact on the activity system, travel patterns of the users will change responding to changes in the transport system. For example: suburban shopping centers will attract shoppers deterring them from driving downtown. Another example would be the impact on international trade due to ameliorated border crossing procedures, and delay reductions.

The Government Impact: The impact on different level of government, municipal or federal. Technology can positively impact government operations and data collection processes. Better decision making will be the result of providing a better tool for the analysis of alternatives. 


\section{The Basic Framework for Predicting Impact}

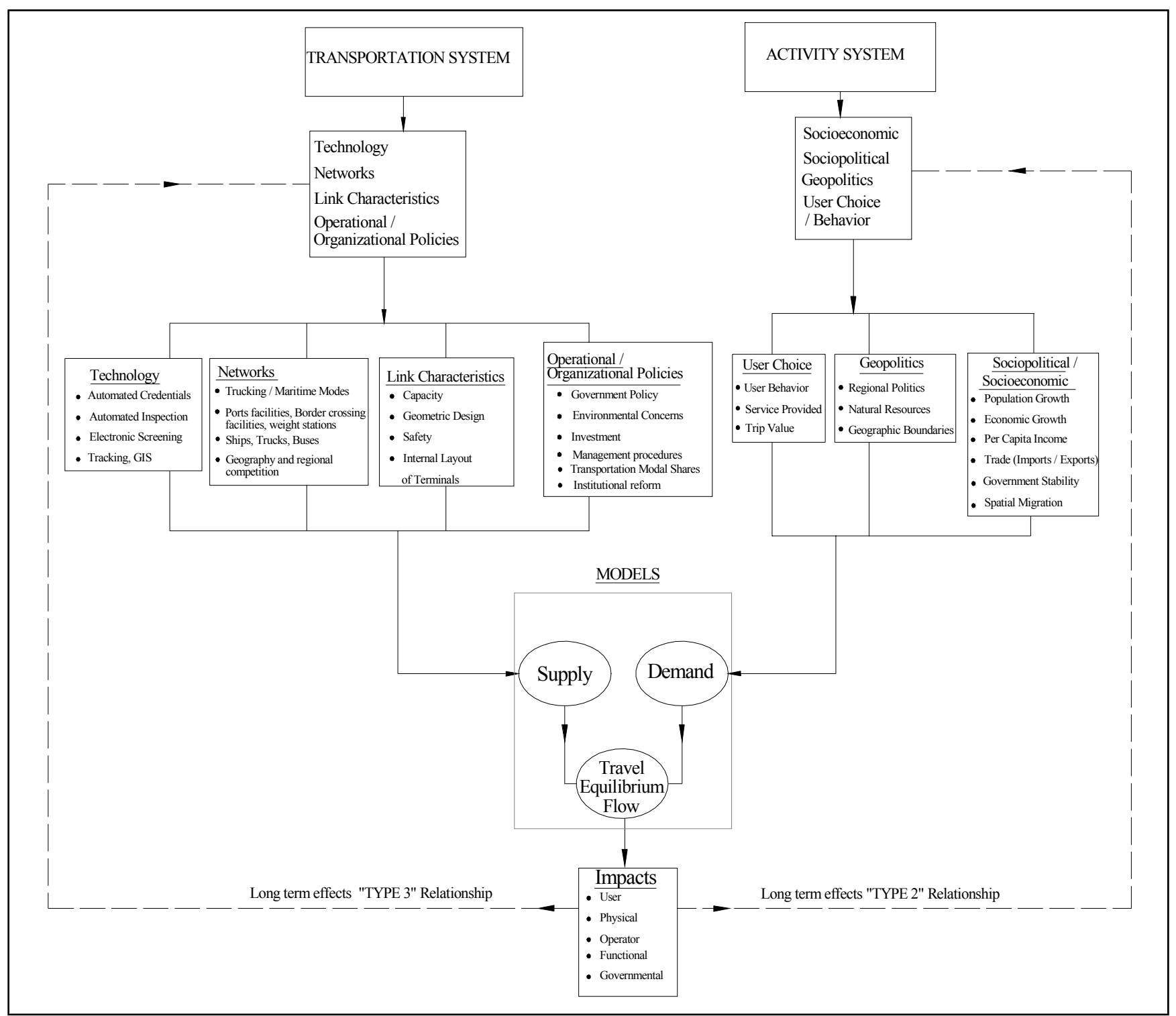

Figure 4.1: The basic framework for prediction of flow 


\section{CHAPTER 5}

\section{CONCEPTUAL LEVEL COMPUTATION}

\subsection{Introduction}

In Chapter 4 the broad form of the framework was developed. The next task is to focus on further developing the framework to introduce elements specific to CVOs. The link between Manheim's concept and microeconomics will be developed. Movement of goods is the focus of the study rather than the movement of people. By introducing ITS technology to CVOs, one would expect changes to occur. The changes occurring to the transportation system can be quantified and modeled by using microeconomic theory.

The demand function (d) is developed to indicate the relation between flow volume and level of service or price. The demand for transportation arises from the Activity System. The supply or performance function (Sp) is developed to indicate the relationship between the flow volume of a particular system and its corresponding level of service or price. It can be viewed as a process in which resources are consumed to produce transportation services in a particular environment. When the factors that affect the quality demanded and the factors that determine the quantity supplied are equal statically, equilibrium is reached. Shifts in the Activity System or transportation system will result in a shift of the equilibrium point resulting in change in flows or levels of service or both.

\subsection{Developing a Supply Function}


As discussed in Section 4.2.1, the supply function must consider the transportation systems options. For CVOs the options influencing the supply are shown below in further detail:

a) Technology: ITS/CVO technology has many important applications to the movement of goods. It can positively influence both the trucking and maritime mode's freight activity by providing timely information on traffic condition, trouble spots. ITS /CVO technologies have proven to be effective and cost effective. See Table 5.1 for some ITS/CVO and their benefits. In this study, alternatives will concentrate on incorporating new technologies to improve freight operations, on the administrative level as well as the roadside level and affecting both private and public sectors.

On the administrative level, improving and organizing government documents and permits, is the primary goal. This activity consists of orders to shippers, request for freight service and all the paperwork that a motor carrier is required to fill pertaining registration, paying fuel taxes, and permits. EDI provides the transfer of all these transaction via modem without human intervention and can be centralized for other government agencies for these benefit. In addition, the automation of these credentials will define the operation and parameters for motor-carriers, and identify motor-carrier businesses, drivers and commercial vehicles.

The roadside level uses for ITS/CVO are many. Traffic sensing and control devices, satellite sensing systems and automated routing scheduling systems can all have important applications to commercial vehicle operations. Global Positioning Systems (GPS), GIS, AVI, WIM, and LPR can provide better fleet control by making use of real-time data. The electronic clearance systems will allow for more efficient 
inspection activities for proper documentation, and better safety standards. Weighing a vehicle while in motion will be an incentive for motor-carriers; delay reduction will motivate carriers to comply with regulations. The aggressiveness level of investing in technologies can be categorized into low or high market penetration alternatives.

The major contributors of delay at seaports are the lengthy clearance procedures, complicated administrative procedures, and unnecessary formalities, which translates into an economic loss. By enhancing efficiency of marine container transportation, container-processing time at seaports will be kept to a minimum. The processing time of containers at sea ports in an important factor related to the efficiency and production (Kaysi 1996). Queuing time and inspection time will be reduced as well. Ground transportation operations can also be enhanced by technology. Using information technology to achieve objectives will focus on improving private sector fleet management, streamlining government/regulatory functions, and roadside activities such as improving safety and clearance systems.

b) The Network and link characteristics: Historically, urban planners relied on studying commuter traffic, in order to forecast growth. Freight traffic usually constitutes $5 \%$ to $15 \%$ of total traffic. Road networks are designed with the primary goal of moving people not goods. This has forced the freight transportation industry to adapt to a network designed primarily to commuters. The problem is magnified in developing countries since the network is sometimes not equipped or designed for motor vehicles. In some cases residential routes are used as shipping routes resulting in road damage, population, congestion, and safety hazards. There is a need to restrict 
these routes risking longer more expensive alternatives. Routes used for freight mobility have equipped to handle the heavy loads.

Substandard geometric design and the lack of maintenance activities have a dramatic impact on the characteristics of a link. Steep grades and sharp turning radii will cause problems for large shipping trucks. It is important for developing countries to upgrade, improve and maintain international roads.

In addition, facilities such as, ports, weigh stations, border-crossing facilities, warehouses, and storage facilities are all part of a network. The location of terminals with respect to shippers and receivers will affect costs (Ogden 1988). Trip length, hours of operations, vehicle type, and route choice are some factors influenced by location. Truck and ship technology has evolved and allowed for bigger heavier loads to be transported.

c) Operational / Organizational Policies: Environmental issues are of main concern. Noise, water, and air pollution are factors associated with freight transportation, and push government into making decisions regarding taxation, regulation and enforcement. Operation and management practices use logistics to optimize operation and scheduling activities. The increase use of logistics has resulted in more frequent deliveries resulting in lesser quantity demanded.

\subsubsection{The Supply Model}

When trying to model supply for CVOs, options such as presented above may be considered to develop a supply function. The supply function (Sp) is a volume-price relationship that relates the user cost or price of travel on particular facility, to the 
function of its uses. The equation below shows a linear relationship between a travel time component and a monetary value for making a trip.

$$
P=a t+f
$$

Where: $\quad p$, is the price or user cost of travel (in dollars) for a particular volume $q$. $a$, is the parameter representing user time cost. (in dollars per unit

of time)

$$
t \text {, is the time spent travelling (in unit of time) }
$$

To determine the supply function, a performance function has to be developed first. Performance function relates the travel time to the volume travelling on the facility. The following equation shows this relationship.

$$
t=t o+b q
$$

Where: $\quad t$, is the average travel time for volume $q$.

to, is the travel time for near zero volume on the facility.

$b$, is the travel time congestion parameter for that facility. $q$, is the volume using the facility.

By substituting $t$ into the first equation, the user cost or price volume relation would be as follows:

$$
\begin{gathered}
p=a(t o+b q)+f \\
p=a t o+a b q+f \\
\text { or } \\
p=\tau+\zeta q+f
\end{gathered}
$$


Where: $\tau$, is a constant parameter representing the value of the minimum trip time. $\xi$, is a parameter representing the joint effect of the travel time increases and the unit time value (so that $\xi,=a b$ )

See figure 5.1 for a graphical representation of the supply function.

Consider the example of a truck carrying goods from A to B. The facility is a toll highway with a capacity of $2,200 \mathrm{veh} / \mathrm{hr}$. The fare price " $f$ " includes the toll fee and other costs totaling $\$ 45$. The distance between A and B is 400 miles. The average travel time to make the trip is 8 hours based on a " $q$ " of 1,100 vehicles/hr using the facility. If the unit time factor " $a$ " is $\$ 5 / \mathrm{hr}$, and "to" between A and B is 6 hours. The cost function would be:

$$
\begin{gathered}
t=t o+b q \rightarrow 8 \mathrm{hrs}=6 \mathrm{hrs}+(b) *(1,100 \mathrm{veh} / \mathrm{hr}) \rightarrow b=0.0018 \mathrm{hr} \cdot \mathrm{hr} / \mathrm{veh} \\
\xi=a b \rightarrow \xi=(5 \$ / \mathrm{hr}) *(0.0018 \mathrm{hr} . \mathrm{hr} / \mathrm{veh}) \rightarrow \xi=0.009 \mathrm{hr} / \mathrm{veh} \\
\tau,=(5 \$ / \mathrm{hr}) *(6 \mathrm{hrs}) \rightarrow \tau,=30 \text { dollars } \\
\mathrm{C}=30 \$+(q) 0.009 \$ . \mathrm{hr} / \mathrm{veh}+45 \$ \rightarrow \mathrm{C}=88.0 \text { dollars }
\end{gathered}
$$

\subsection{Developing a Demand Function}

As discussed in earlier chapters, modeling transportation demand for developing countries is essential to better predict the impact on flow volumes. Variables that have the most impact on demand and are included in one function, and the linear regression analysis technique is used establish a relationship between the variables and the demand volume. The options affecting demand are shown below: 
a) Socioeconomic variables: The socioeconomic variables that have an affect on CVOs are many. For instance, population growth will increase the demand for transportation. If there is an increase in demand and a stagnant supply, the transportation system will be congested. For example, in developing countries, many people are moving away from the countryside to live in the capital or large urban areas for better jobs and more opportunities. In developed countries, people tend to migrate away from the city center, and live in small communities in the vicinity of the city, and they rely mostly on private automobiles for transportation to the work place. Whatever the case may be, an increase in population has to be accounted for hen predicting future demand. A nations economic health will greatly affect freight transportation and is also influenced by sector change. A sector change is when a country shifts from its reliance from one sector to another. This will result in a shift from one mode to another, ultimately affecting freight activity. For example, China has been focusing on shifting from the processing of raw materials to the production of semi-processed goods that have a higher value and are lighter in weight. Resulting changes in the demand for transportation.

b) User choice or travel options: individual travelers are faced with several alternatives to make a trip, similarly, shippers have a choice. Information on what is moving or being moved, for what purpose, and between what points in the system is important for policy issues. The shipper will make his decision based on a perceived perception of the service offered by a particular operation. 
c) Geopolitics: Political issues have a tremendous impact on the potential of growth. Politically motivates embargoes and regional politics are examples. Predicting these political activities is next to impossible, especially in underdeveloped countries where political issues are more dynamic in nature. However, assessing political activities can be achieved through the observation and investigation of the following: government expenditures, foreign aid and investment, and regional politics. International trade is greatly affected by international political decisions. For this reason, a political factor has to be included in the demand function.

\subsubsection{The Demand Model}

The following sections will focus on the element that should be considered for modeling demand, considering a broad scope of variables.

The two basic sets of variables in a demand function (D) are the activity system variables and service attributes. Table 4.3 shows some relevant factors that might be helpful to develop a demand function. These factors have to be outlined and modeled in an attempt to identify their effects on the flow. The volume of flow is defined as a function of the activity system option and the level of service or price experienced:

$$
q=\alpha-p \beta
$$

Where $q$ : is the flow volume

$\alpha$ and $\beta$, are the parameters representing the activity system (socioeconomic, sociopolitical)

$$
p \text { : is the trip price }
$$


Refer to Appendix A for the basic algebraic forms of demand functions.

Figure 5.2 illustrates the linear demand function. The figure shows demand as a function of price. For a particular volume " $q \mathrm{a}$ ", " $p \mathrm{a}$ " designates the price for travel. As demand volume increases, price is reduced. The reciprocal is true as well, as price increases $(p b)$ the demand volume will decrease $(q b)$.

Consider the example of a trip between two towns. Both towns are characterized by their population, employment levels, and income levels. The parameter " $\alpha$ " represents the potential for travel between the two towns based on utility. The parameter " $\beta$," represents the change in demand for each units of travel for travel between the towns are $2,200 \mathrm{veh} / \mathrm{hr}$ and $-13.7 \mathrm{veh} / \mathrm{hr}$ per minute respectively. The travel demand function becomes:

$$
q=1670-8.4 p
$$

\subsection{Equilibrium}

The basic feature of an equilibrium analysis asserts that actual flow in the system is not the maximum a facility can handle, the actual flow depends on the level of service offered by that facility. For a particular transportation system a supply function (Sp) will define a relationship for cost in terms of volume. The activity system will produce a demand function (D) relating the volume in terms of price. The actual flow in the system is the intersection point of the demand and performance function. Refer to Figure 5.3 for the graphical representation of simple equilibrium between the price function and the demand function developed in earlier sections.

$$
q=1670-8.4 p
$$




$$
p=30+(q) 0.075+45
$$

Solving for the equilibrium numerically shows values for:

Equilibrium volume " $q e$ " is $950 \mathrm{veh} / \mathrm{hr}$.

Equilibrium cost or price " $p e$ " is 88 dollars.

Equilibrium is attained when the supply equals the demand. The demand and supply functions are measured on a common scale, in this case it bis the price, or cost to make a trip. This is achieved by price oscillation as shown in Figure 5.4. The figure shows that for a specific volume " $q 1$ ", the corresponding price for that volume is " $p 1$ "; but if the price was " $p 1$ ", then the volume of travel expected is " $q 2$ ". In turn, if the volume traveled on the facility is " $q 2$ ", then the price that consumers are willing to pay becomes " $q 3$ ", and so forth till equilibrium is (nearly) reached.

The process of approaching equilibrium is called the "cobweb model", and in this particular case the equilibrium is set to be converging. If the demand function is flatter and the supply function is steeper then there will not be a converging point. See Figure 5.5 .

The demand function becomes flatter when the volume for travel is not highly dependent on price. This is called an elastic demand. It signifies that the need for travel is pressing, it is considered a luxury. In the case of inelastic demand, the volume is highly dependent on the price signifying a large dependence on travel.

\subsubsection{Shifts in the Activity System and the Transportation System.}

The effects of a change in fare prices or capacity improvement plan will result in a shift in the supply function. If the fare price increases the shift in the supply function 
will be in the upward direction. The result of an improvement plan will cause the shift in the downward direction as shown in Figure 5.6.

For instance, the implementation of an electronic toll will allow vehicles to bypass long lines at tollbooths. Resulting in a more efficient operation. If the demand function stays static, the volume that will flow on the facility will increase " $q 1$ "at a lower price " $p 1$ ".

The shift in the activity system is caused from the increased demand on the facility. The factors affecting this shift where discussed in earlier chapters. This shift in demand from "D1" "D2", will cause the equilibrium point to shift from "e0" to "e1", resulting in lower levels of service due to an increase in volume from " $q 0$ " to " $q 1$ ". The new equilibrium point become "e2" shows that the system can accommodate more volume " $q 2$ " at a price " $p 2$ ".

For example, trade agreements like the North American Free Trade Agreement (NAFTA) and common markets such as the European Union will impact freight transportation. Tariffs and trade restrictions will decrease in an effort to promote international trade restrictions will decrease in an effort to promote international trade.

Another example would be the privatization of government entities. Mexico, Poland, and the United Kingdom are examples of countries that have successfully privatized and deregulated the transportation sector. Funding and investing in the construction of new facilities such as airports or toll road usually will improve the system and increase travel. Operation policy, include pricing issues, types of services, scheduling, financing and regulatory decisions, all affect flow in the system. For instance, an increase in fuel taxes will decrease the already low margin of profit 
associated with a trucking companies thus altering their operation (e.g. scheduling, pricing) to optimize the profit margins.

\subsubsection{Quantifying User Benefits}

The concept of consumer surplus is based on the idea that there is difference between what consumers pay and what they are willing to pay. It is used as a measure of worthiness or benefits. Every shipper or user expects to receive a benefit when shipping. The user benefit is equivalent to the value of the trip to the user measured by the amount a traveler is willing to spend for a trip.

The demand function may be used to indicate the willingness of trip makers to pay for a trip. Figure 5.7 shows " $p$ ", as the maximum price for which consumers are willing to pay to make a trip. The trips demanded at that price are shown as "qo". If a price increase $(\Delta p)$ occurred, the new price is denoted as "pi" and is equal to ( $\left.p_{0}+\Delta p\right)$, some traveler will not be willing to pay this increase in price since they where getting just enough benefits for making a trip at the previous price. The benefits no longer attract them to make a trip or ship some goods. The new volume hence becomes $q_{0}+\Delta q$ (where $\Delta q$ is negative if $\Delta p$ is positive and vice versa). Referring to Figure 5.7 the following benefits can be computed for both before and after change in price.

Before price change: $\left(p_{0}, q_{0}\right)$

. Total benefit to users: $(\mathrm{C}+\mathrm{E})+(\mathrm{B}+\mathrm{D})+\mathrm{A}$

- Net user benefit or consumer surplus: $A+B+D$

After price change: $(p \mathrm{i}, q \mathrm{i})$

- Total benefit to users: $\mathrm{A}+\mathrm{B}+\mathrm{C}$ 
- Net user benefit or consumer surplus: $(A+B+C)-(B+C)=A$

The comparison of differences in benefit for a change from: $\left(p_{0}, q_{0}\right)$ to $(p \mathrm{i}, q \mathrm{i})$

- The Gross Benefit: D + E

- Consumer surplus: B + D

- User Cost: B - E

In summary the implications of this decision-making process is useful for capital budgetary issues. Developing countries can apply this framework to investigate the potential of implementing ITS/CVO technologies and their benefits. 


\begin{tabular}{|c|c|c|}
\hline Study & $\begin{array}{l}\text { Services/Technologies } \\
\text { Examined }\end{array}$ & Reported Benefits or Cost Savings \\
\hline $\begin{array}{l}\text { HELP / } \\
\text { Crescent }\end{array}$ & $\begin{array}{l}\text { Weigh-in-Motion } \\
\text { Automatic Vehicle identification } \\
\text { Automatic Vehicle Classification }\end{array}$ & 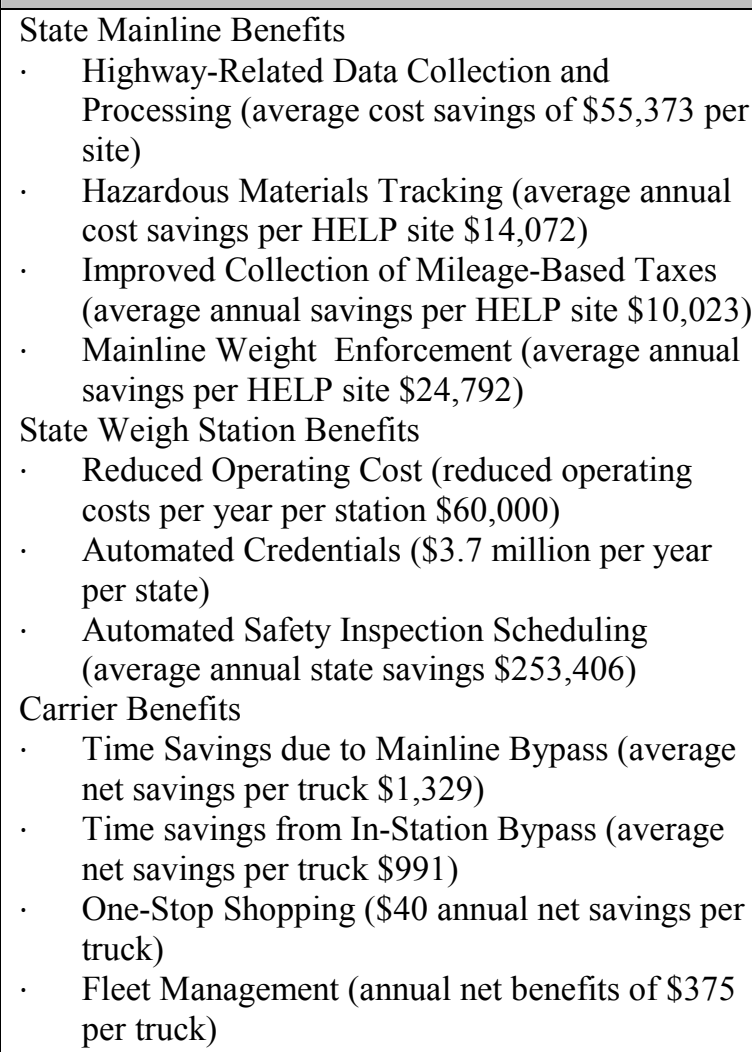 \\
\hline ATA & $\begin{array}{l}\text { CV Administrative process } \\
\text { Electronic Clearance } \\
\text { Automated Roadside Safety Inspection } \\
\text { On-Board Safety Monitoring } \\
\text { Hazardous Materials Incident Response } \\
\text { Freight Mobility }\end{array}$ & $\begin{array}{l}\text { CV Administrative process (2:1 to } 19.8: 1) \\
\text { Electronic Clearance (1.9:1 to } 7.5: 1) \\
\text { Automated Roadside Safety Inspection * } \\
\text { On-Board Safety Monitoring }(<.1: 1 \text { to } .5: 1) \\
\text { Hazardous Materials Incident Response }(.4: 1 \text { to } 3: 1) \\
\text { Freight Mobility }(1.5: 1 \text { to } 5: 1)\end{array}$ \\
\hline Purdue & $\begin{array}{l}\text { Weigh-in-Motion } \\
\text { Automatic Vehicle identification } \\
\text { Automatic Vehicle Classification }\end{array}$ & 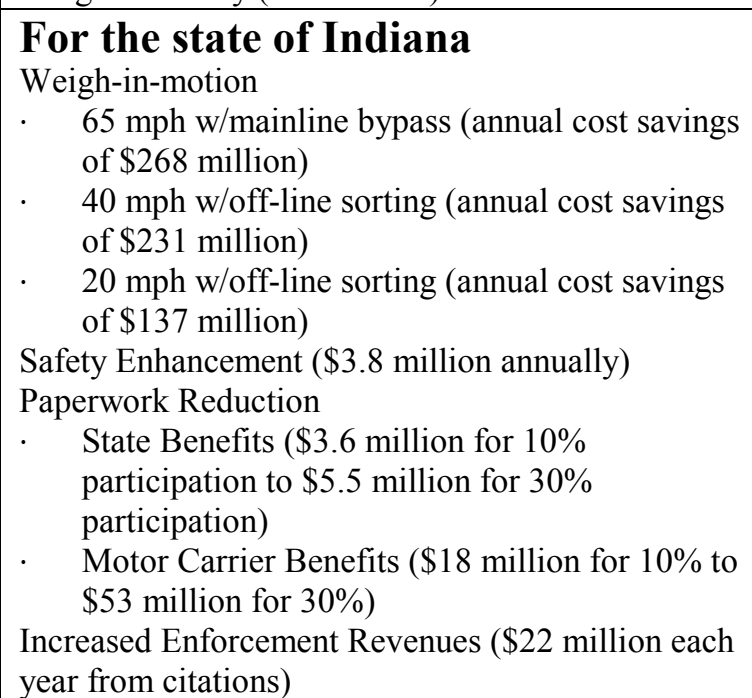 \\
\hline
\end{tabular}

Table 5.1 Reported benefits or Cost Savings associated with ITS/CVO implementation. Source: Budgetary Implications of ITS/CVO for State Agencies. FHWA, 1998.

* Positive benefits with no direct costs 


\begin{tabular}{|c|c|c|c|c|c|c|c|}
\hline \multirow{3}{*}{ Country } & \multicolumn{7}{|c|}{ CAPACITY } \\
\hline & \multirow{2}{*}{$\begin{array}{c}\text { Merchant } \\
\text { Marine } \\
\text { ships }\end{array}$} & \multirow{2}{*}{$\begin{array}{c}\text { Highways } \\
\text { (Km) }\end{array}$} & \multirow{2}{*}{$\begin{array}{c}\text { Railways } \\
\text { (Km) }\end{array}$} & \multirow{2}{*}{$\begin{array}{c}\text { Port/ } \\
\text { Harbors }\end{array}$} & \multirow{2}{*}{$\begin{array}{l}\text { Runways } \\
>3000 \text { m }\end{array}$} & \multicolumn{2}{|c|}{ Containers } \\
\hline & & & & & & GRT* & DWT** \\
\hline Algeria & 78 & 102,424 & 4,772 & 13 & 8 & 928 & 1,094 \\
\hline Egypt & 161 & 64,000 & 4,751 & 9 & 11 & 1,225 & 1,899 \\
\hline Iran & 135 & 162,000 & 7,286 & 15 & 36 & 3,465 & 6,128 \\
\hline Lebanon & 62 & 6,350 & 222 & 12 & 1 & 258 & 392 \\
\hline Libya & 30 & 83,200 & 0 & 9 & 24 & 615 & 1,044 \\
\hline $\begin{array}{c}\text { Saudi } \\
\text { Arabia }\end{array}$ & 76 & 162,000 & 1,390 & 11 & 30 & 1,009 & 1,329 \\
\hline Syria & 125 & 40,480 & 1,998 & 4 & 5 & 376 & 555 \\
\hline Turkey & 528 & 381,631 & 10,386 & 9 & 17 & 6,205 & 10,400 \\
\hline
\end{tabular}

Table 5.2: Relevance data for capacity analysis, for selected developing countries. Source: http://www.odci.gov/cia/publications/factbook. Estimates for year 1987.

* GRT: Gross Register Ton ('000)

** DWT: Deadweight Ton ('000) 


\begin{tabular}{|c|c|c|c|c|c|}
\hline \multirow{3}{*}{ Country } & \multicolumn{5}{|c|}{ DEMAND } \\
\hline & \multicolumn{2}{|c|}{ Trade (Billion \$) } & \multirow{2}{*}{$\begin{array}{c}\text { GDP: Real } \\
\text { Growth Rate }(\%)\end{array}$} & \multirow{2}{*}{ Population Growth } & \multirow{2}{*}{$\begin{array}{l}\text { GDP per Capita } \\
\text { Growth (\$) }\end{array}$} \\
\hline & Import & Export & & & \\
\hline Algeria & 10 & 13.1 & 2.5 & 2.14 & 4,000 \\
\hline Egypt & 15.5 & 5.1 & 5.2 & 1.86 & 4,400 \\
\hline Iran & 15.6 & 19 & 3.2 & 2.04 & 5,500 \\
\hline Lebanon & 7.559 & 1.018 & 4 & 1.62 & 4,400 \\
\hline Libya & 6.2 & 9 & 0.5 & 3.68 & 6,700 \\
\hline Saudi Arabia & 25.4 & 56.7 & 4 & 3.41 & 10,300 \\
\hline Syria & 5.7 & 4.2 & 4.6 & 3.23 & 6,600 \\
\hline Turkey & 46.7 & 26 & 7.2 & 1.6 & 6,100 \\
\hline
\end{tabular}

Table 5.3: Relevance data for demand analysis, for selected developing countries.

Source: http://www.odci.gov/cia/publications/factbook. Estimates for year 1987. 


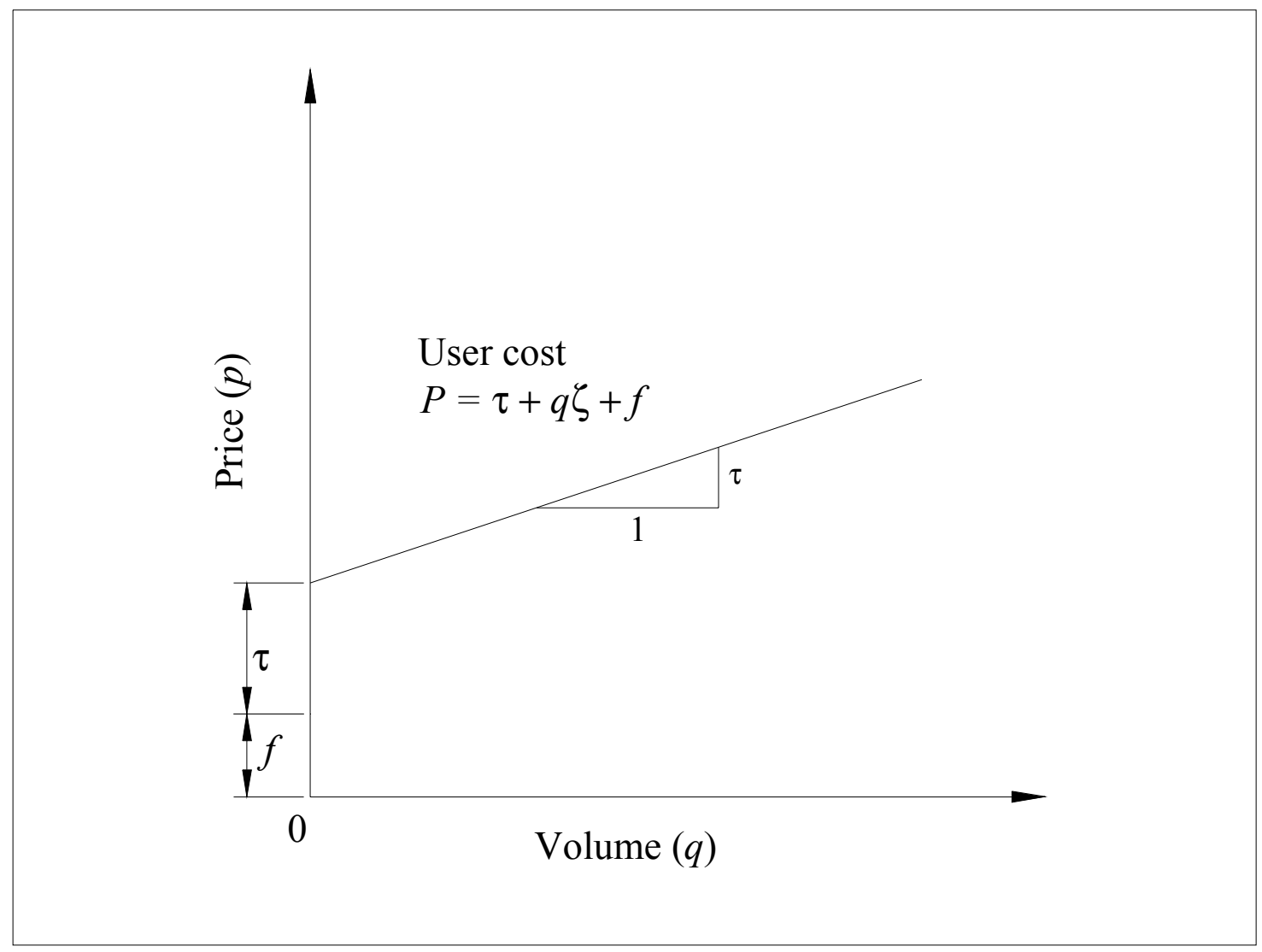

Figure 5.1: An illustrative User Cost or Price-Volume Relationship 


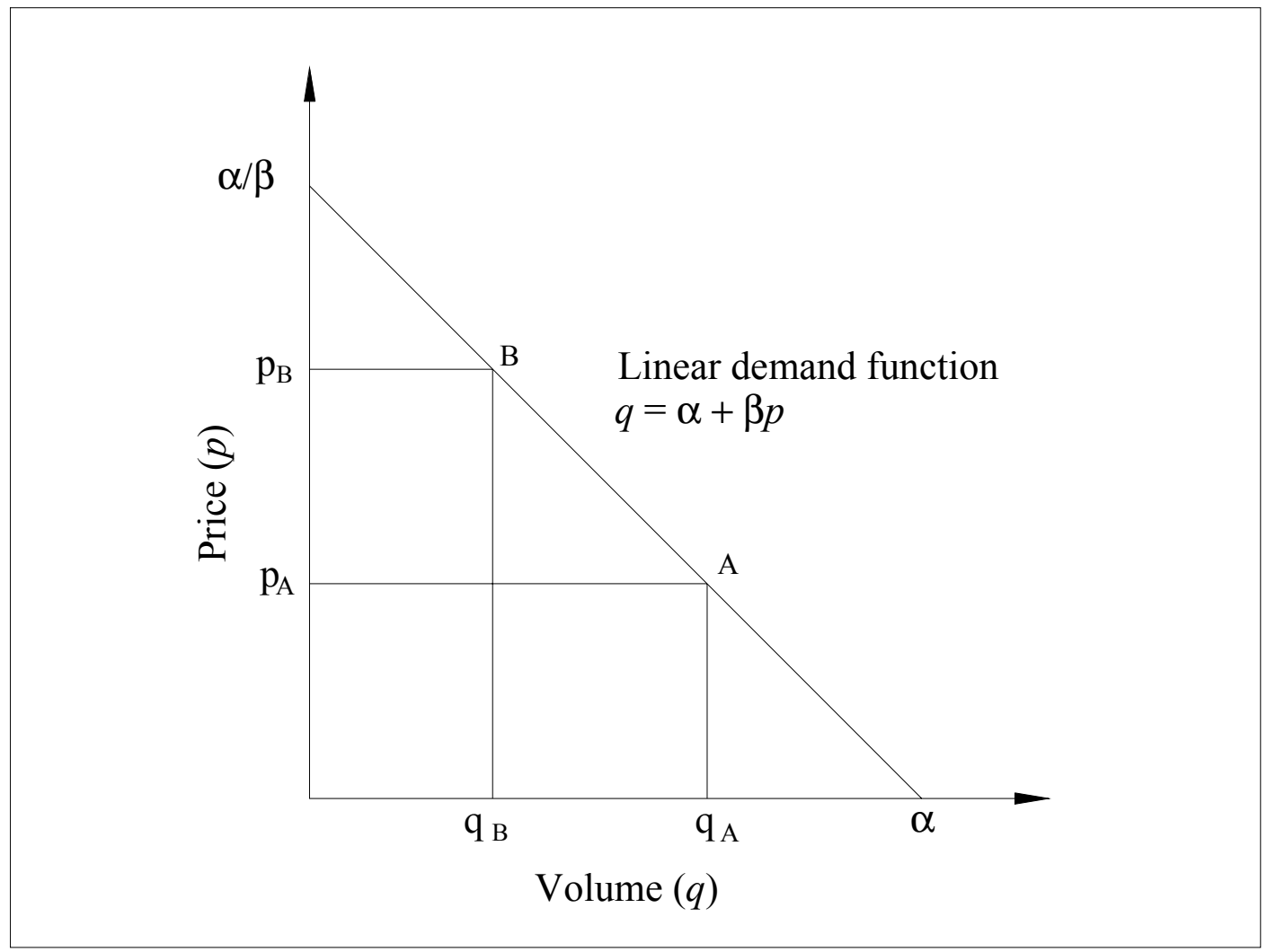

Figure 5.2: An Illustrative Linear Demand Function 


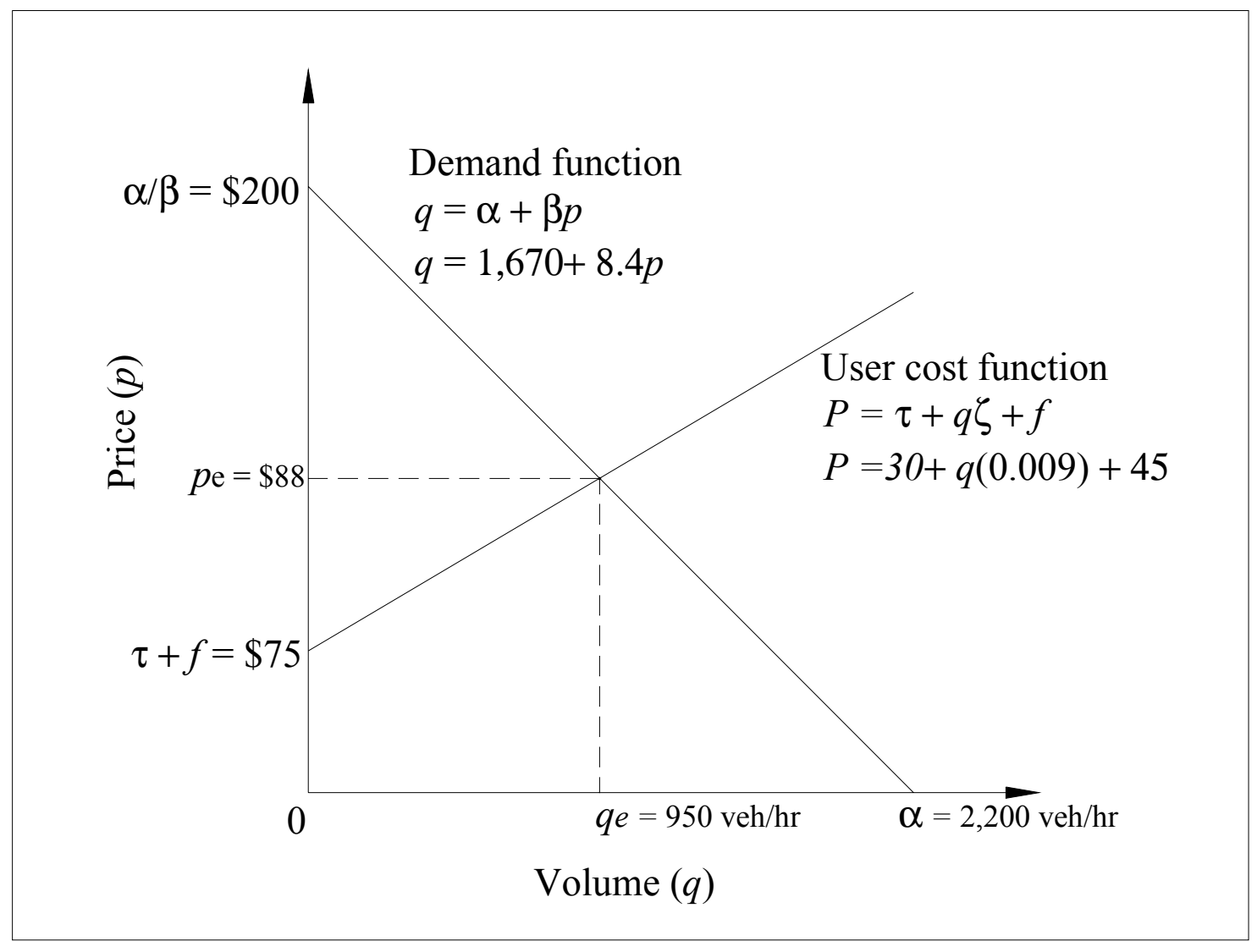

Figure 5.3 :An Illustration of Equilibrium Between Demand and Supply 


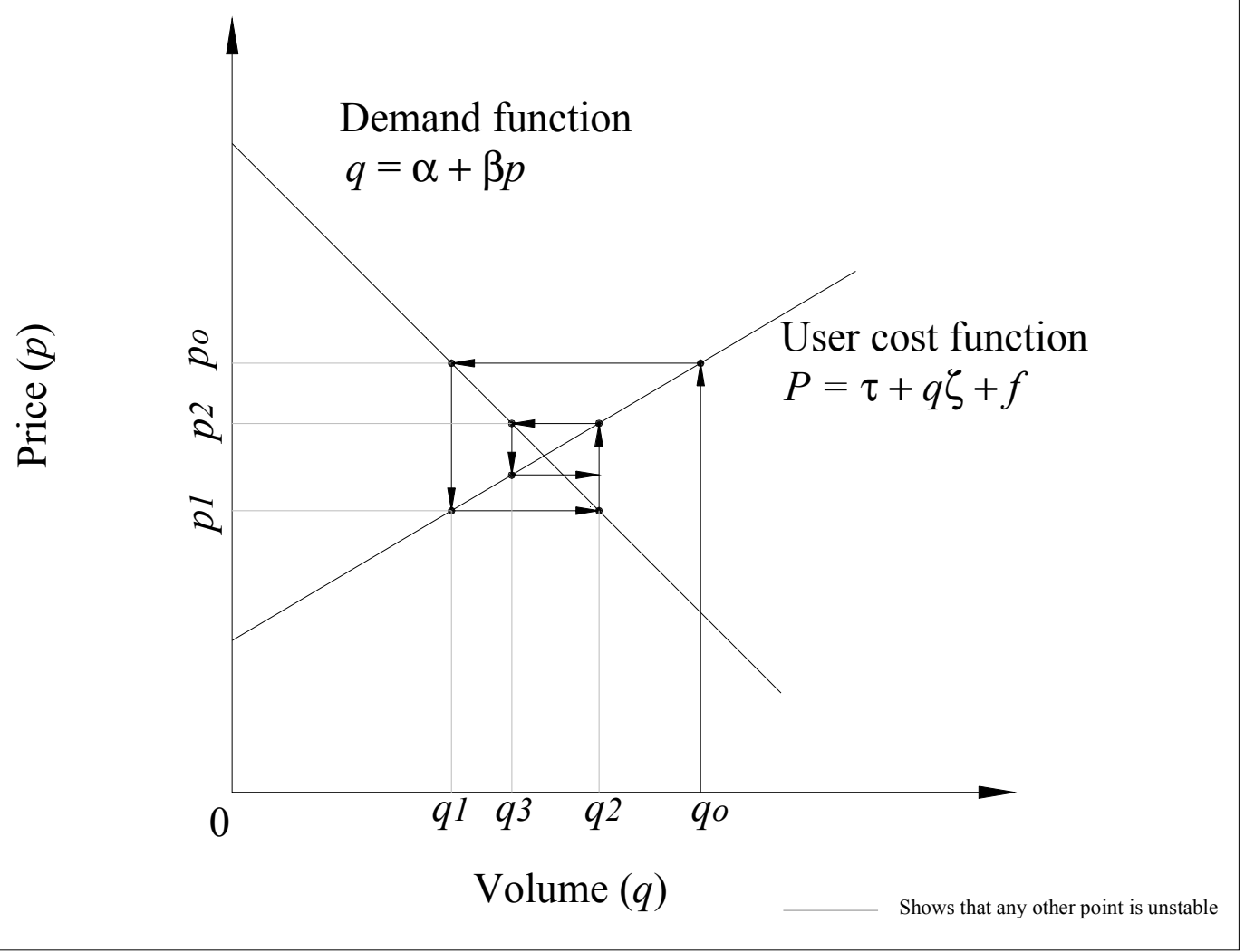

Figure 5.4 :An Illustration of Converging Equilibrium Between Demand and Suppl! 


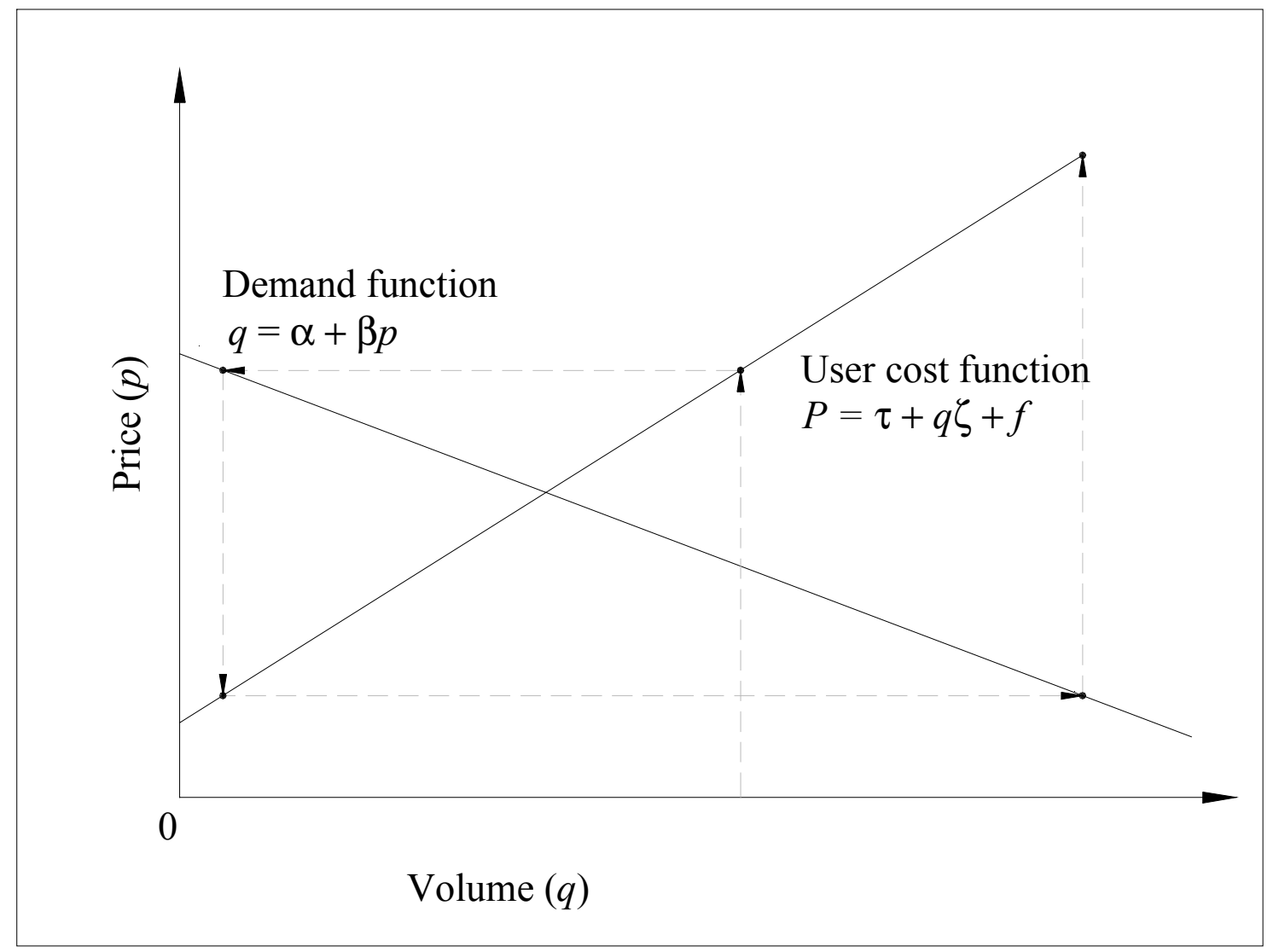

Figure 5.5:An Illustration Diverging Equilibrium Between Demand and Supply 


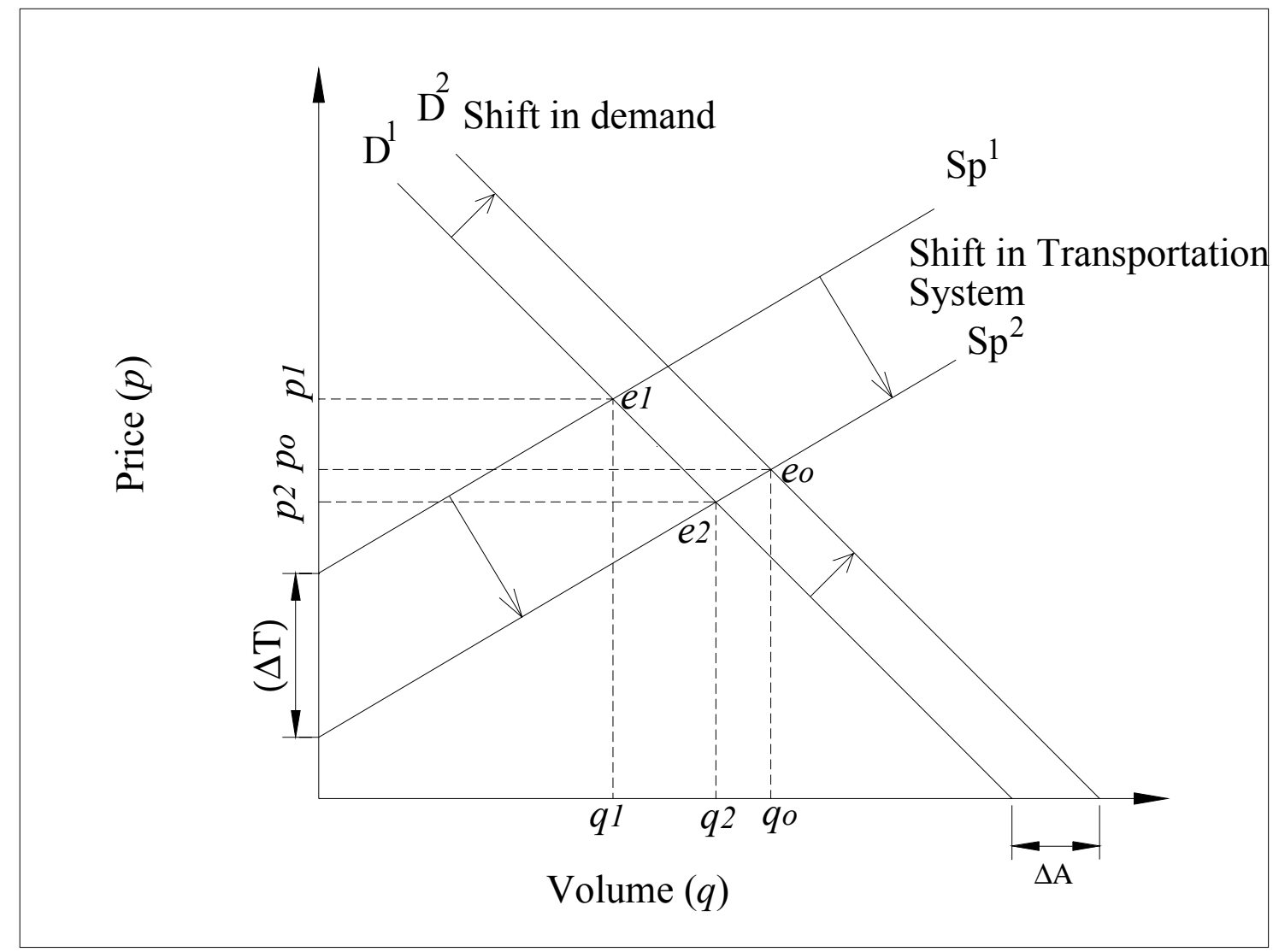

Figure 5.6: Activity System and Transportation System Shifts 


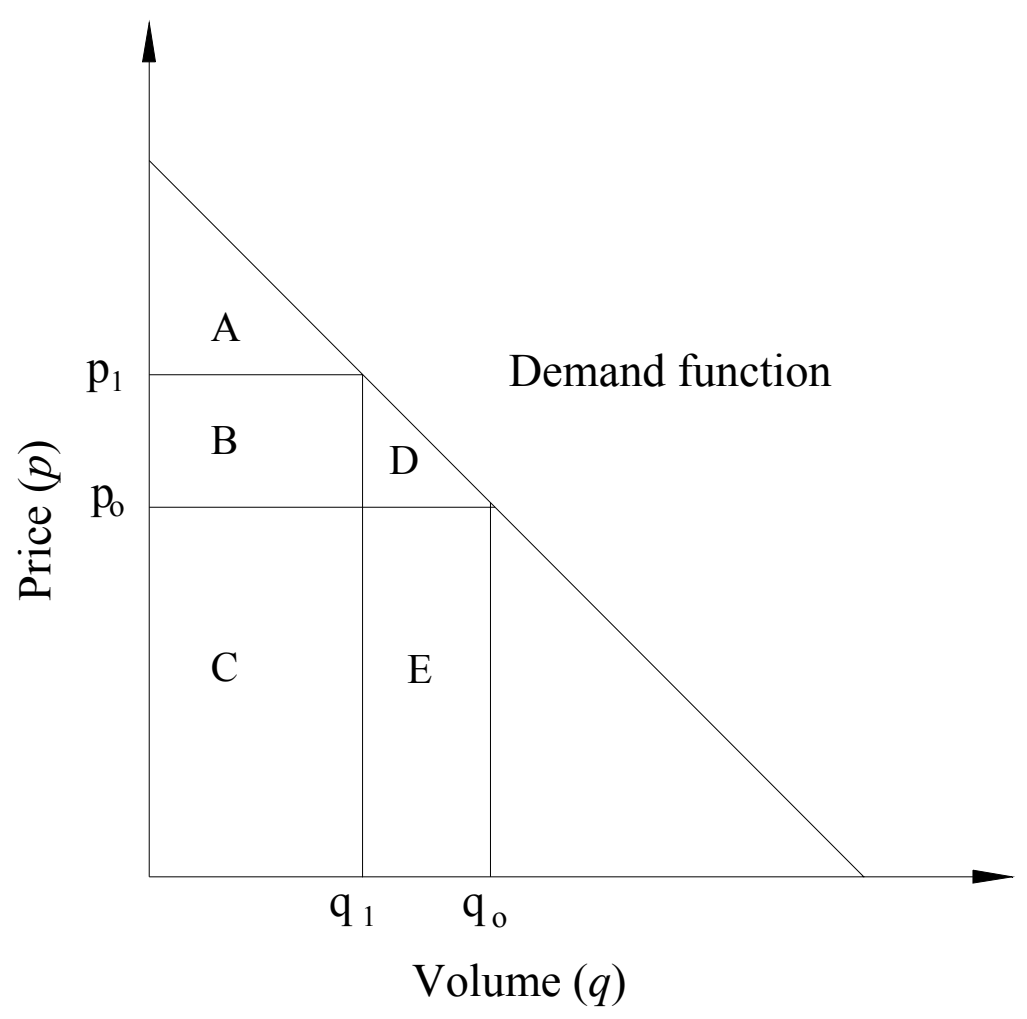

Figure 5.7: Consumer Surplus Concept 


\section{CHAPTER 6}

\section{IMPLEMENTATION OF THE FRAMEWORK}

This chapter will help identify and formulate the data required for predicting

impacts of new technology on a transportation system. An example is used to illustrate how to formulate demand. The example will be for the country of Lebanon and determine demand for freight movement.

\subsection{Introduction}

The analysis process will follow the procedure outlined in previous chapters and will follow the following steps:

1. Identification of variables

2. Demand and supply formulation

3. Solve for equilibrium

4. Determine new supply function based on new improvement alternatives

5. Determine net benefit using the Consumer Surplus concept.

There is a distinction between the types of operations that fall under a CVO classification. The socioeconomic and geopolitical activities will be considered separately and a demand function will be developed to estimate the demand for freight transportation as a measure of price. The transportation system will determine the physical characteristic of the network as a measure of price. For this example, a supply function will not be derived; instead it will be shown schematically to determine an 
equilibrium point. The equilibrium point will determine the volume of flow at a specific price.

In general, there are four types of freight traffic, refer to Appendix A for the definition in most cities. Longhaul traffic, shorthaul extraregional traffic, local distribution traffic and through traffic. For the purpose of this study the focus is on a typical freight route consisting of 2 modes. The operation chosen for this study involves the trucking and the maritime modes, and includes long haul traffic, short haul traffic, through traffic and local traffic. The network and its characteristics are shown in Figure 6.1. The pilot route considers freight arriving in by ship to the port of Beirut. If the cargo has a final destination to another country in the Middle East with no port capabilities, the cargo has to be cleared, transferred from ship to truck, inspected at the border, and finally delivered.

\subsection{Socioeconomic and Sociopolitical Variables Considered}

This section will show how to formulate demand for freight transportation in the country of Lebanon. The task will be split into two sections, starting with a brief background on the country of Lebanon to explain the relevant socioeconomic and sociopolitical issues at hand. The second section will systematically show how a function for demand can be established.

\subsubsection{Background on socioeconomic and political issues for the country of Lebanon}

Lebanon is a country in post-war reconstruction phase. Fifteen years of conflict have devastated the economy and reduced the per capita income by two-thirds. This was 
due to the widespread destruction of the infrastructure and the dislocation of the population. About 200,000 professional and skilled Lebanese have left the country, causing a shortage in skilled staff (The World Bank, May 1994).

The year 1991 has marked the end of the 16 years of civil war that seriously damaged the country's economic infrastructure. Peace has allowed for economic recovery, by enabling the central government to regain control of key ports and government facilities, to collect taxes, and to reestablish Beirut City as the banking hub of the Middle East. Lebanon's economy has made impressive gains. Since the launch of an eighteen billion dollar reconstruction project the "real GDP grew $8 \%$ in 1994 and $7 \%$ in 1995 before Israel's Operation Grapes of wrath in April 1996 stunned the economic activity. During 1992-97, annual inflation fell from more than $170 \%$ to $9 \%$, and foreign exchange reserves jumped to more than $\$ 4$ billion from $\$ 1.4$ billion. The funds that fuel the reconstruction process are partly foreign investment partly capital investments and partly private funds. The $\$ 2$ billion reconstruction of Beirut's central business district, allowed for the reopening of the stock market in January 1996, and encouraged international banks and insurance companies to return which resulted in a temporary stable economy and currency.

In an effort to allow for reconstruction and growth, the Council for Development and Reconstruction (CDR) has allocated $\$ 10.5$ Billion over a ten-year period for a comprehensive reconstruction plan that started in 1994. The transportation sector alone accounted for $27 \%$ of the total investment, totaling \$2.9 Billion. Over 600 construction contracts were signed by local and international companies in an effort to improve the transportation infrastructure. 


\subsubsection{Demand Estimation}

To formulate a demand function, the first step involves a decision matrix to identify the most relevant variables to be considered. For the purpose of this study the variables chosen for are: Economic Index GDP Growth Percentage Rate, Population Index Per Capita Growth Percentage Rate, and Political Stability Attribute denoted as X1, $\mathrm{X} 2$, and $\mathrm{X} 3$, respectively. These variables intend to capturing social, economical and political variables and to relate them to volume of freight. Regression analysis is performed and the results presented in Table 6.1 show that the equation with three variables is more accurate for prediction future flow. Comparing the $r^{2}$ values, the equation producing a $\mathrm{r}^{2}$ value closest to 1.0 , is the equation with the strongest correlation between the variables and the actual TEU growth rate percentage denoted as $\mathrm{Y}$.

Using the equation with three variables, Table 6.2 shows the estimated TEU growth percentage rate denoted as "Y" and the actual volume of TEU moved denoted as "V".

Table 6.3 shows the correlation between the estimated volumes and the average total transportation cost. The total transportation average cost is assumed on the basis of, as demand increases the cost to transport goods decreases. The values are plotted producing the demand function. This demand function can be used in conjunction with a supply function to determine an equilibrium point. Once the equilibrium point is established, quantifying user benefits can be attained from using the consumer surplus concept shown in Figure 5.7 


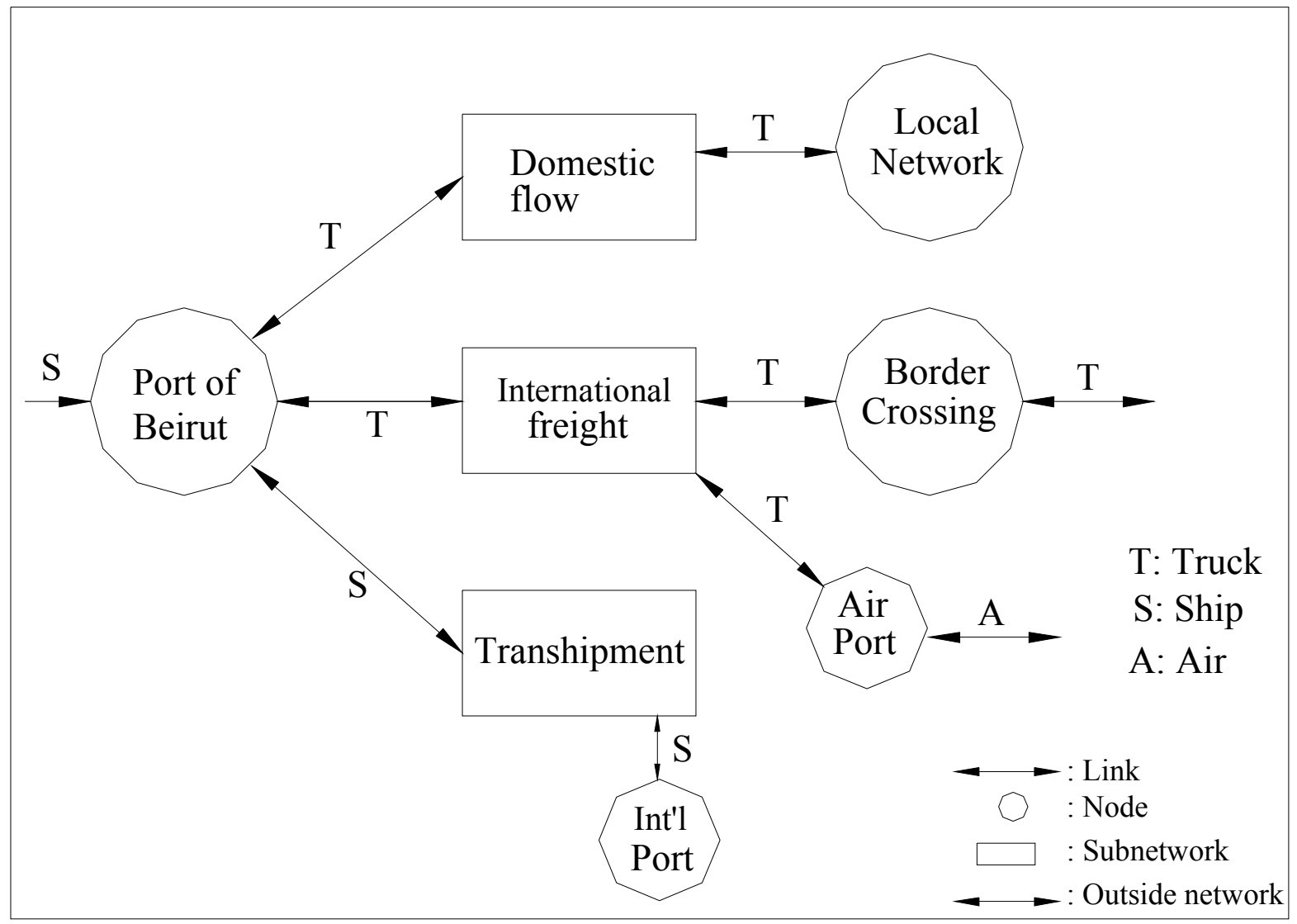

Figure 6.1: The Network for " the lebanon example." 


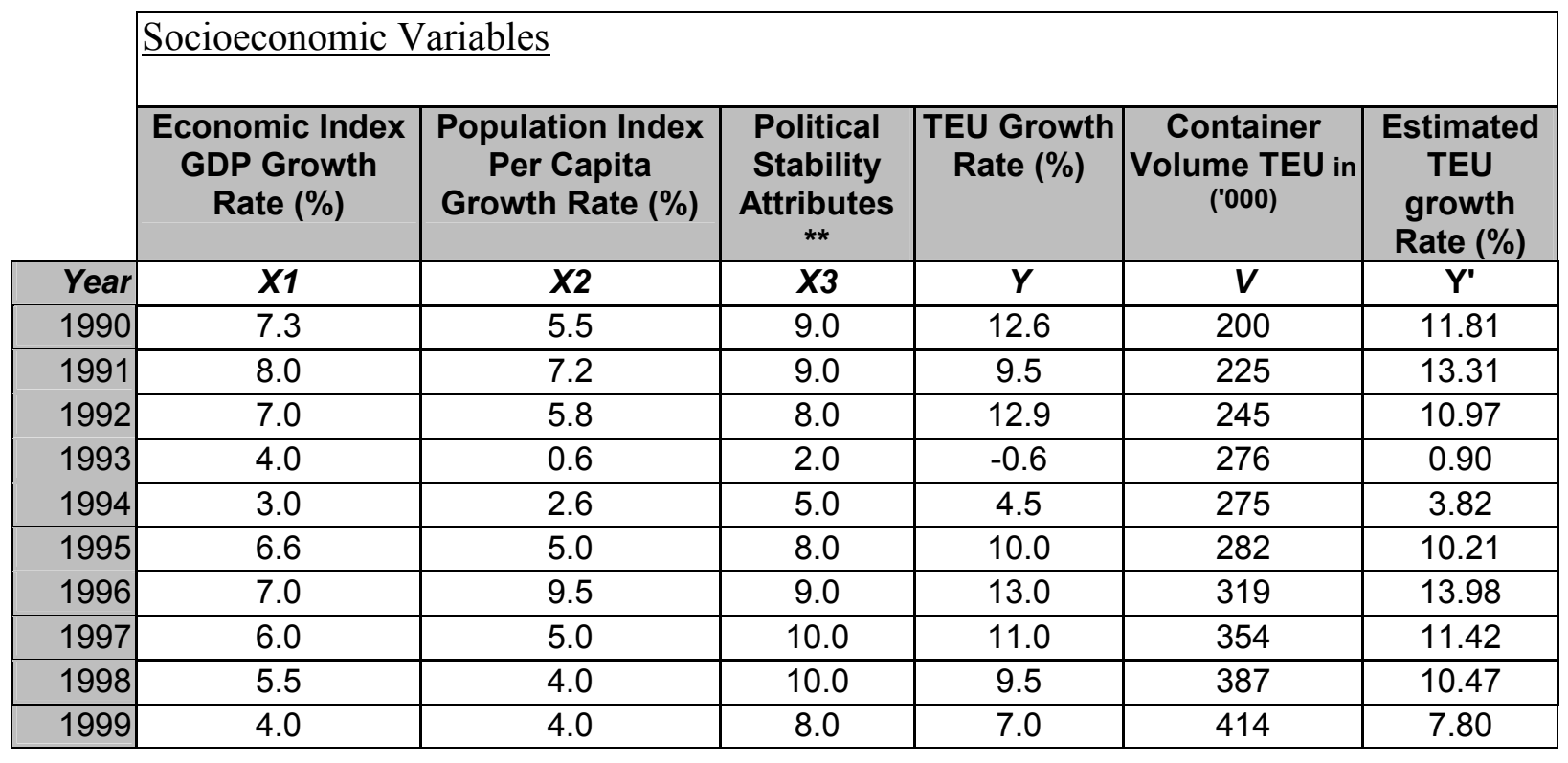

Table 6.1:Some socioeconomic Variables for Lebanon (1992 - 2010)

** Values predicted on a scale of one to ten. One being a bad political situation and ten being a good one.

Source of Data: HPC Hamburg Port Consulting GmbH, Germany. Equipment Planning Study.1997 


\begin{tabular}{|c|c|c|c|c|c|c|c|c|c|c|c|c|c|c|}
\hline & m1 & m2 & m3 & se1 & se2 & se3 & Seb & sey & b & r2 & $\mathbf{F}$ & df & ssreg & $\begin{array}{c}\text { ssresi } \\
\text { d }\end{array}$ \\
\hline$Y=m X 1+m X 2+m X 3+b$ & 702 & 593 & 0.813 & 407 & 543 & .710 & 3.116 & 2.200 & -3.889 & .816 & 10.380 & 7.000 & 151.010 & 33.932 \\
\hline$Y=m X 1+m X 2+b$ & 0.996 & 0.974 & & 0.547 & 0.785 & & 3.096 & 2.458 & -1.437 & 0.738 & 11.300 & 8.000 & 136.600 & 48.245 \\
\hline$Y=m X 1+m X 3+b$ & 0.894 & 1.319 & & 0.372 & 0.544 & & 2.826 & 2.228 & 5.399 & 0.785 & 14.628 & 8.000 & 145.234 & 39.713 \\
\hline$Y=m X 2+m X 3+b$ & 0.764 & 0.999 & & 0.411 & 0.419 & & 2.411 & 2.244 & -1.565 & 0.782 & 14.360 & 8.000 & 144.653 & 40.293 \\
\hline$Y=m X 1+b$ & 2.106 & & & 0.537 & & & 3.302 & 2.755 & -3.171 & 0.630 & 15.350 & 9.000 & 116.600 & 68.345 \\
\hline$Y=m X 2+b$ & 1.534 & & & 0.344 & & & 1.887 & 2.530 & -1.656 & 0.688 & 19.881 & 9.000 & 127.310 & 57.633 \\
\hline$Y=m X 3+b$ & 1.437 & & & 0.368 & & & 2.970 & 2.765 & -1.753 & 0.627 & f15.177 & 9.000 & 116.100 & 68.846 \\
\hline
\end{tabular}

\begin{tabular}{|l|l|}
\hline se1 & The standard error values for the coefficients $\mathrm{m} 1, \mathrm{~m} 2, \ldots, \mathrm{mn}$. \\
\hline Seb & The standard error value for the constant $\mathrm{b}$ \\
\hline $\mathbf{r 2}$ & $\begin{array}{l}\text { The coefficient of determination. Compares estimated and actual y-values, and ranges in value from } 0 \text { to 1. If it is 1, } \\
\text { there is a perfect correlation in the sample 3/4 there is no difference between the estimated } y \text {-value and the actual y- } \\
\text { value. At the other extreme, if the coefficient of determination is 0, the regression equation is not helpful in predicting a } \\
\text { y-value. For information about how } \mathrm{r} 2 \text { is calculated, see Chapter five. }\end{array}$ \\
\hline sey & The standard error for the y estimate. \\
\hline $\mathbf{F}$ & $\begin{array}{l}\text { The } \mathrm{F} \text { statistic, or the F-observed value. Use the } \mathrm{F} \text { statistic to determine whether the observed relationship between } \\
\text { the dependent and independent variables occurs by chance. }\end{array}$ \\
\hline df & $\begin{array}{l}\text { The degrees of freedom. Use the degrees of freedom to help you find F-critical values in a statistical table. Compare } \\
\text { the values you find in the table to the F statistic returned by LINEST to determine a confidence level for the model. }\end{array}$ \\
\hline ssreg & The regression sum of squares. \\
\hline ssresid & The residual sum of squares. \\
\hline
\end{tabular}

Table 6.2 Values from the Regression Analysis. 


\begin{tabular}{|c|c|c|}
\hline $\begin{array}{c}\text { Estimated Container } \\
\text { Volume TEU in ('000) }\end{array}$ & $\begin{array}{c}\text { Estimated TEU } \\
\text { growth Rate (\%) }\end{array}$ & $\begin{array}{c}\text { Average Total } \\
\text { Transportation Cost (\$) }\end{array}$ \\
\hline $\mathbf{Y}$ & $\mathbf{Y}$ & $\mathbf{C}$ \\
\hline 200 & 11.81 & $5,000,000$ \\
\hline 224 & 13.31 & $4,500,000$ \\
\hline 253 & 10.97 & $4,000,000$ \\
\hline 281 & 0.90 & $3,500,000$ \\
\hline 284 & 3.82 & $3,000,000$ \\
\hline 295 & 10.21 & $2,500,000$ \\
\hline 325 & 13.98 & $2,000,000$ \\
\hline 370 & 11.42 & $1,500,000$ \\
\hline 412 & 10.47 & $1,000,000$ \\
\hline 455 & 7.80 & 500,000 \\
\hline 491 & 10.27 & 100,000 \\
\hline
\end{tabular}

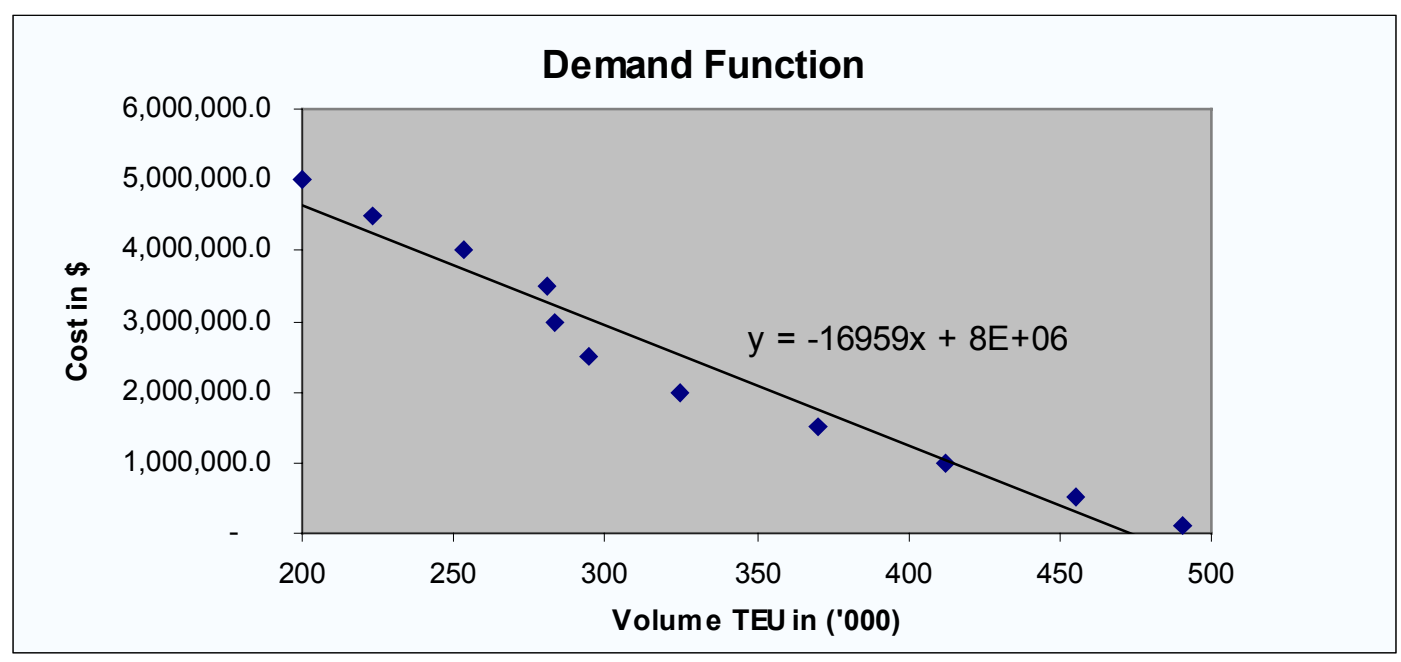

Table 6.3: The correlation of predicted flows and its cost 


\section{CHAPTER 7}

\section{CONCLUSIONS AND RECOMMENDATION}

The strength of the activity-based approach used in this study is the Transportation System and the Activity System within a framework for a comprehensive analysis approach. This approach allows for the global representation of the transportation system. The link between this approach and Microeconomic theory allows for the computation of demand and supply of the system for the Activity System and the Transportation System receptively. The equilibrium point is the intersection of the demand and the supply curves and denotes the flow volumes on a facility. The Consumer Surplus concept allows for the computation of the net benefits associated with an improvement plan. This framework can be a helpful tool to strengthen budgeting and expenditure control, as a direct result of better decision-making.

Fast development is typical in developing countries. This has to be counteracted with quick and well-planned improvement actions. Effective planning on the project level is a must. Proper coordination of transportation project will eliminate redundancy, thus decreasing cost. Build-operate-transfer (BOT) projects and new flexible deregulation laws are increasingly involving the private sector in transportation; a positive step that can prove detrimental if not coordinated properly on the global level. Policy makers and analyst have to predict the impact of this technology for a more costeffective development, especially due to the large investment usually associated with transport. They have to determine the most beneficial way to spend the money. 
Modern CVO technology provides an opportunity to further investigate the potential implementation of such technology in developing country. The transfer of this technology presents a number of challenges. One of these challenges stems from the dynamic nature of socioeconomic and sociopolitical issues. Developing a framework to understand the impact of this technology has to capture these issues. There is a need to further the understanding of these variables. This study focuses on the general socioeconomic and sociopolitical variables involved to formulate demand. More focused work is needed in terms of identifying the obstacles associated with user response. In general, the overall attitude towards technology application needs to be further studied. In addition, it is recommended for future research to focus on further investigation of the political variable, which will result in a more accurate formulation of future demand.

Prediction of flows is an attempt to predict travel equilibrium for any proposed changes in the transportation system. The changes resulting from the activity system such as population growth are identified by a shift in the demand function. This study formulates a demand function but does not formulate a supply function. It is recommended for future research to focus on developing a supply function, which involves a thorough investigation of the CVO network and an understanding of the resources consumed to provide a certain transportation service.

Work on developing data collection schemes is needed. A supply function requires data about freight flows, capacity of the CVO network, the type of goods etc. In developing countries in general, data is lacking and sometimes inadequate which makes it a challenge to properly formulate the supply function. Using CVO technology for this purpose is topic worth investigating for future research. 


\section{REFERENCES}

1. Bernstein, D., and Kanaan, A., Automated Vehicle Identification: Technologies and Functionalities. Massachusetts Institute of Technology, Cambridge, MA. IVHS Journal, 1993. Vol.1 (2), pp. 191-204

2. Cervero, R., Manson, J. Transportation in Developing Countries: Conference proceeding, Sept. 1998.

3. Dawkins, Janine; Daniel, Janice. Technology transfer to the Caribbean case study of Kingston, Jamaica. Transportation Research Record \# 1637 Sept 1998, p24-32.

4. Dimitriou, Harry. Transportation planning for Third World Cities. Library of congress, ISBN:0-415-00448-9 N.Y. 1990

5. Shunk, A. Gordon. The Effects of Added Transportation Capacity. Conference Proceedings December 16 and 17, 1991 Prepared by: Texas Transportation Institute, Planning Support Branch (HEP-22) Federal Highway Administration U.S. Department of Transportation.

6. Fernandez, J. E. and Friesz, T. L. (1983) Equilibrium Predictions in Transportation Markets: The state of the art. Transportation Research Board, 17B, 155-172 
7. Jaramillo, Adriana, Technology and Society, Bulletin of Science v 16 \# 1-2 1996, STS Press University Park PA. P24-27

8. Kanafani, A., Transportation Demand Analysis. Mc Graw-Hill, Inc. 1983.

9. Kaysi, I., "New Horizons in Engineering and Technology in the Arab Region", American University of Beirut. May 1996.

10. Larson, R., and Odoni, A., Urban Operation Research. Massachusetts Institute of Technology, Prentice-Hall, Englewood Cliffs, New Jersey, 1997.

11. Manheim, M., Fundamentals of Transportation System Analysis, Volume 1.Basic Concept. MIT Press, Massachusetts 1979.

12. Olberding, J.C., Using License Plate Recognition Technology to Enforce Out-ofService Commercial Vehicles. Transportation Center, University of Kentucky, Lexington KY.

13. Wohl, M., and Hendrickson, C., Transportation Investment and Pricing Principles: An Introduction for Engineers, Planners and Economists. Carnegie-Melon University, Pittsburgh, PA. John Wiley and Sons, 1984. 
14. The World Bank. Lebanon-Revenue Enhancement and Fiscal Management / Technical Assistance Project. May 1994. www.worldbank.org/pics/pid/lb5340.txt

15. S. Department of Transportation. The Federal Highway Administration. A Guide to Developing a State ITS/CVO Business Plan. Prepared by Cambridge Systematics, Inc. Cambridge, Massachusetts. October 1996.

16. U.S. Department of Transportation Research and Special Programs Administration. U.S. Department of Transportation Research and Development Plan. First Edition. Volpe National Transportation Systems Center Cambridge, MA. May 1999. www.volpe.dot.gov/pubs/rdplan99/toc.html

17. U.S. Department of Transportation. Federal Highway Administration (FHWA). Budgetary Implications of ITS/CVO for State Agencies. June 1998.

18. The Intelligent Vehicle Highway Society of America. Strategic Plan for Intelligent Vehicle-Highway Systems in the United States. IVHS America, 1992.

19. Transportation Research Board Intermodal Marine Container Transportation, Impediments and opportunities. TRB Special Report 236, 1992.

20. U.S. Department of Transportation. Transportation Statistics Annual Report 1997: Mobility and Access. Bureau of Transportation Statistics, Washington, DC. 1997. www.bts.gov/programs/transtu/tsar/tsar97/front.pdf 
21. U.S. Department of Transportation. Federal Highway Administration (FHWA). Description of ATIS/CVO Functions. Publication Number: FHWA-RD-95-201. April 1997

22. U.S. Department of Transportation. The Federal Highway Administration (FHWA). Human Factors Design Guidelines: for Advanced Traveler Information System and Commercial Vehicle Operations). 1998. www.bts.gov/ntl/DOCS/atis/index.html 


\section{BIBLIOGRAPHY}

1. Alam, G., "Characterizing Uncontrolled Traffic Conditions In Post War Beirut" The American University of Beirut. Beirut, Lebanon October 1997

2. Jay L. Devore. "Probability and statistics for engineering and the sciences". California Polytechnic State University. Brooks/Cole publishing company.

3. Hayuth, Y. 1987. Itermodality: Concept and practice. Lloyd's of London Press, London.

4. Jenson, J., "Using Satellite Technology for Voice and Data Transfer in Kentucky Vehicle Enforcement", University of Kentucky Transportation Center, Lexington KY.

5. Harvey, J. Miller. Towards Consistent Travel Demand Estimation in Transportation Planning: A Guide to the Theory and Practice of Equilibrium Travel Demand Modeling. Report prepared by, Department of Geography, University of Utah. Salt Lake City, Utah. Nov 1997. www.bts.gov/tmip/papers/feedback/miller/toc.htm

6. Monsere, C., Economic Analysis of the Application of Intelligent Transportation Systems Technologies for Commercial Vehicles Operations to the Mid-Continent Corridor. Master's thesis, Department of Civil Engineering, Iowa State University, Ames, IA, December 1997 
7. Sanjay Bapna Ph.D., Jigish Zaveri Ph.D., Z. Andrew Farkas Ph.D. Benefit-cost assessment of the commercial vehicle information systems and networks (CVISN) in Maryland. National Transportation Center, Morgan State University Baltimore, Maryland. November 1998.

8. Federal Highway Administration, Office of Highway Information Management. Vehicle Travel Information System (VTRIS), User's guide. Office of Highway Information Management, FHWA, U.S. Department of Transportation, 1995.

9. Assessment of Intelligent Transportation Systems/ Commercial Vehicles Operations (ITS/CVO) User Services Qualitative Benefit/Cost Analysis. Report No MC-96-028, FHWA, U.S. Department of Transportation, Washington D.C., 1996.

10. U.S. Department of Transportation. Federal Highway Administration. "Oregon Green Light”. February 1996.

11. ITS/CVO cost benefit analysis state processes for commercial vehicles (draft). National Governor's Association. Prepared by Apogee, Inc. October 1997.

12. Commercial vehicle operations one-stop electronic purchasing and processing ITS operational test. The Western Highway Institute, Denver, Co, 1997.

13. Equipment Planning Study. HPC Hamburg Port Consulting GMBH, Germany 1997.

14. Walton, Jennifer, Using $L P R$ to detect $C V O$ registration and other plate related violations. Kentucky Transportation Center, University of Kentucky. Lexington, KY. 1999. acvo.uky.edu/CVOz/CaseStudies.html 
15. Advantage I-75 Motor Carrier Fuel Consumption Individual Evaluation. Center for Transportation research and Education, Iowa State University, Ames, Iowa, October 1997.

16. "States' Successful practices Weigh-In-Motion Handbook", Federal highway Administration, Center for Transportation Research and Education, Iowa State University, December 1997

17. HTTP://www.bts.gov/ntda/cfs/desc.html

18. www.worldbank.org

19. www.theodora.com/wfb/lebanon transportation.html

20. www.odci.gov/cia/publications/factbook/le.html

21. www.iurd.ced.berkeley.edu/pub/frame abswp9807.html

22. http://www.dot.gov/http://www.dot.gov/ 
APPENDIX A 


\section{The Microeconomic Demand Theory}

The Microeconomic Demand Theory is useful to develop a framework for the analysis of demand. The approached is at two levels. The user will make specific decisions about which mode to use? When to make the trip, and how to make the trip? The user will base his decision on his perception of the system and transaction patterns in the activity system, which is called the consumer demand. The market demand is the result of all individual consumer demand functions, aggregated to form the market demand.

The consumer demand theory looks at understanding the behavior of an individual making decisions. For the purpose of developing a demand function, the following should be examined.

1. How consumers may differ in behavior?

2. How socioeconomic activities may affect consumer behavior?

3. How will changes in the transportation system affect the choices of the consumer?

The following basic assumptions have to be made about the consumer

1. The consumer has more than one choice. If the consumer did not have a choice on how to spend their resources, there would be no need to try to predict his or her behavior. In a sense, the decision has been made for him.

2. The consumption of goods is always associated with a utility or a satisfaction to the consumer. The utility will differ for each consumer. In transportation, the utility comes from the characteristics of the system such as travel time, or travel cost. 
3. The consumer has a set of consistent preferences based on the utility of the goods. The consumer will not always choose the goods that yield higher utility; it will be dependent on budget constraints and the choices available. The stability of the consumer implies that as long as he belongs to a socioeconomic group, the utility will not vary hence the preference will not change.

4. The consumer is said to be insatiable. Which means, having more goods is always better than having less. This implies that the consumer when faced with different quantities of the same goods, he will opt to choose the one that has the larger quantity. The utility function associated with consumption of certain goods cannot be decreasing.

5. The consumer has budget and time constraints. There is a limited supply of goods, and consumption will be limited to the amount of time and money that a consumer is willing to allocate. 


$$
\mathrm{Y}=\mathrm{a}+\mathrm{bXi}
$$

Where: "Y" is the volume of freight flow.

"X" represents a single service attribute or activity system variable.

“a,b" can be estimated using linear regression from observation of " $\mathbf{Y}$ " and "X"

$$
\begin{gathered}
a=\frac{n\left(\sum x_{i} y_{i}\right)\left(\sum x_{i}\right)\left(\sum y_{i}\right)}{n\left\{\sum\left(x_{i}^{2}\right)\right\}-\left(\sum x_{i}\right)^{2}} \\
b=\frac{\left(\sum y_{i}\right)\left\{\sum\left(x_{i}^{2}\right)\right\}-\left(\sum x_{i}\right)\left(\sum x_{i} y_{i}\right)}{n\left\{\sum\left(x_{i}^{2}\right\}-\left(\sum x_{i}\right)^{2}\right.}
\end{gathered}
$$

When using regression analysis, the Standard Error, and the Coefficient of Determination, can be used to test the equation. The variance measures the amount of variability exists in the regression.

$$
\sigma^{2}=\frac{\sum(y i-\hat{y})^{2}}{(n-2)}
$$

The Coefficient of Determination denoted as " $r^{2}$ " can have a value of anywhere from zero to one. One implying a perfect correlation in the sample, and zero represent no correlation making the regression equation useful for the prediction of $y$.

$$
r^{2}=\frac{\sum(y i-\check{y})^{2}-\sum(y i-\hat{y})^{2}}{\sum(y-\check{y})^{2}}
$$

The sample correlation coefficient: 


$$
r=\frac{n \sum x i y i-\left(\sum x i\right)\left(\sum y i\right)}{\sqrt{ } n \sum x i^{2}-\left(\sum x i\right)^{2} \sqrt{ } n \sum y i^{2}-\left(\sum y i\right)^{2}}
$$

The standard error of estimate:

$$
s e^{2}=\frac{\sum(y i-\hat{y} i)^{2}}{(n-2)}
$$

Where: $y i$ : is the observed value for each $i .(i=1, \ldots, n)$

$\hat{y} i$ : is the predicted value. $(\hat{y} i=a+b x i)$

$\check{y}$ : is the mean value of " $y n$ "

$x i$ : is the observed value for each $i .(i=1, \ldots, n)$

$(n-2)$ : represents the degree of freedom.

$n$ : is the sample size

" 2 ”: represents the number of parameters to be estimated 
a) Longhaul Traffic: longhaul traffic is traffic with origin and destinations more than 250 miles apart. Longhaul truckload carriers attempt to organize their operations so as to reduce rehandles or the number of empty miles in order to remain competitive.

b) Shorthaul Extraregional Traffic: Shorthaul extraregional traffic is traffic consisting primarily of delivery movements from wholesale distribution warehouse to distant retail establishments. It is traffic moving within about a 250 -mile radius of the origin. Typically, a delivery is made from the point of origin and to destination and returns to the homebase with an empty backhaul at the end of a working day. Deliveries may also consist of raw materials moving in regional markets. The carrier is typically a private fleet of delivery trucks and drivers, and faces little competition from longhaul truckload carrier because the extensive repositioning between loads drives their costs up. This market is left for private carriers or for contract carriers who specialize in short haul delivery, and design their operations accordingly.

c) Local Traffic: Local traffic typically involves small shipments, local delivery operations. Trips from wholesale distribution centers to retail stores or to local manufacturers with the ability for multiple shipments destined to several receivers or retail stores. In addition, the delivered product is sold to consumers who carry the merchandise home using their private automobiles.

d) Through Traffic: the through trips are trips that move through an area or a country but neither originates nor terminates there. However the trip may involve some processing time. For instance, containers imported from the Far East are usually unloaded in the Seattle/Tacoma area and loaded onto rail doublestack cars for 
transportation in the U.S. markets or grain from the east arriving by rail is stored until it can be exported by ship. 